\title{
Mechanism of Inflammation in Age-Related Macular Degeneration
}

\author{
Francesco Parmeggiani, ${ }^{1}$ Mario R. Romano, ${ }^{2,3}$ Ciro Costagliola, ${ }^{2}$ \\ Francesco Semeraro, ${ }^{4}$ Carlo Incorvaia, ${ }^{1}$ Sergio D'Angelo, ${ }^{1}$ Paolo Perri, ${ }^{1}$ \\ Paolo De Palma, ${ }^{1}$ Katia De Nadai, ${ }^{1,5}$ and Adolfo Sebastiani ${ }^{1}$ \\ ${ }^{1}$ Department of Ophthalmology, University of Ferrara, Ferrara, Italy \\ ${ }^{2}$ Department of Health Sciences, University of Molise, Campobasso, Italy \\ ${ }^{3}$ Department of Ophthalmology, Istituto Clinico Humanitas, Milan, Italy \\ ${ }^{4}$ Department of Ophthalmology, University of Brescia, Brescia, Italy \\ ${ }^{5}$ Center for Retinitis Pigmentosa of Veneto Region, ULSS 15 Alta Padovana, Camposampiero, Italy
}

Correspondence should be addressed to Francesco Parmeggiani, francesco.parmeggiani@unife.it

Received 4 July 2012; Accepted 2 October 2012

Academic Editor: Ahmed M. Abu El-Asrar

Copyright () 2012 Francesco Parmeggiani et al. This is an open access article distributed under the Creative Commons Attribution License, which permits unrestricted use, distribution, and reproduction in any medium, provided the original work is properly cited.

\begin{abstract}
Age-related macular degeneration (AMD) is a multifactorial disease that represents the most common cause of irreversible visual impairment among people over the age of 50 in Europe, the United States, and Australia, accounting for up to $50 \%$ of all cases of central blindness. Risk factors of AMD are heterogeneous, mainly including increasing age and different genetic predispositions, together with several environmental/epigenetic factors, that is, cigarette smoking, dietary habits, and phototoxic exposure. In the aging retina, free radicals and oxidized lipoproteins are considered to be major causes of tissue stress resulting in local triggers for parainflammation, a chronic status which contributes to initiation and/or progression of many human neurodegenerative diseases such as AMD. Experimental and clinical evidences strongly indicate the pathogenetic role of immunologic processes in AMD occurrence, consisting of production of inflammatory related molecules, recruitment of macrophages, complement activation, microglial activation and accumulation within those structures that compose an essential area of the retina known as macula lutea. This paper reviews some attractive aspects of the literature about the mechanisms of inflammation in AMD, especially focusing on those findings or arguments more directly translatable to improve the clinical management of patients with AMD and to prevent the severe vision loss caused by this disease.
\end{abstract}

\section{Introduction}

Age-related macular degeneration (AMD) is a common disease of the central area in the ocular posterior segment, known as the macula lutea. This retinal area is essential for the vision of fine details and the image resolution, capturing the greatest focus of the external light stimuli. In the human macula, there are several recognizable main structures: the neuroretina (NR), composed by the inner neurosensory layer and outer photoreceptor cell layer with the underlying retinal pigment epithelium (RPE); this latter structure is separated from the choriocapillaris (CC) by the Bruch's membrane (BM), a modified basement stratum. The retina contains two types of photoreceptors, rods and cones. The rods are more numerous (about 120 million) and are more sensitive than the cones, being responsible for vision at low light levels (scotopic vision). They are not sensitive to colors and characterized by low spatial acuity. Conversely, the 6 to 7 million cones are active at higher light levels (photopic vision), are capable of color vision, and are responsible for high spatial acuity. The center of the macula, called fovea centralis, is an avascular zone exclusively populated by cones (Figures 1(a) and 1(b) [4]). AMD is due to multifaceted degenerative disorders involving the NRRPE-BM-CC complex at the level of macular region [1-3].

AMD represents the main cause of legal blindness or low vision in those developed countries with the longest 


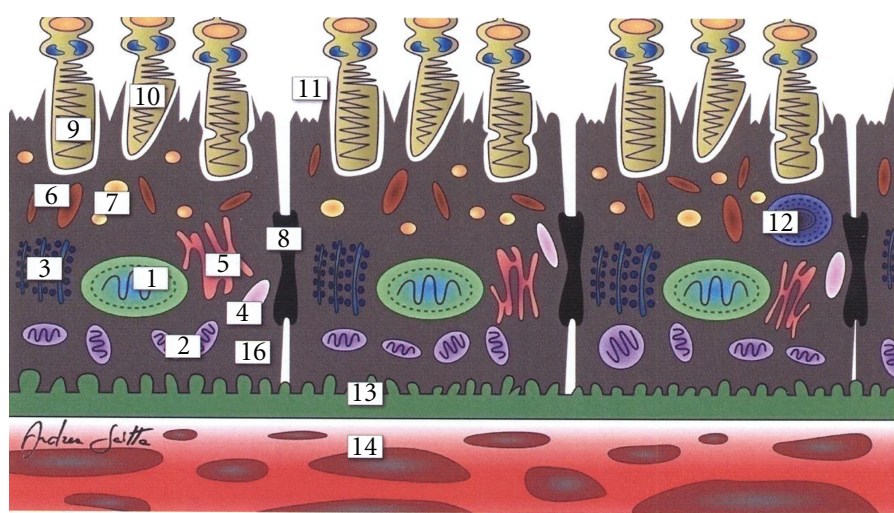

(a)

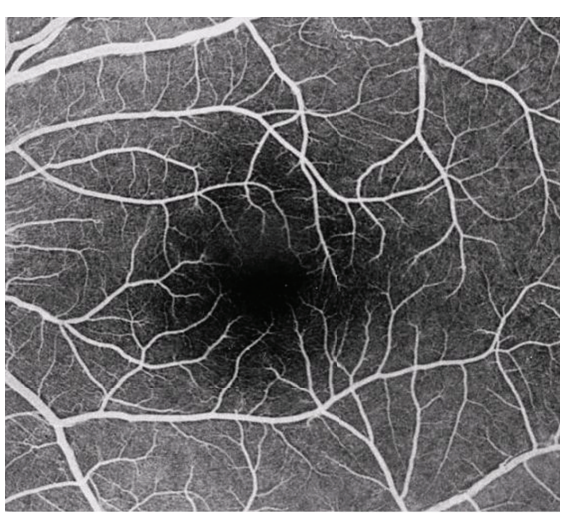

(b)

FIgURE 1: Normal human macula. (a) Schematic cross-sectional illustration of the macular outer segment and, in particular, the cells of the retinal pigment epithelium ((1) nucleus, (2) mitochondria, (3) ribosomes, (4) lysosomes, (5) Golgi apparatus, (6) melanosomes, (7) lipofuscin granules, (8) zonula occludens, (9) photoreceptor (cone), (10) outer segment of cones, (11) phagocytosis of photoreceptorial discs, (12) phagosome, (13) Bruch's membrane, and (14) choriocapillaris). (b) Fluorescein angiography of the macula with its foveal avascular zone (extracted and modified from [4]).

life expectance, especially affecting the elderly people of European descent [3]. In North America, Europe, and Australia, AMD accounts for up to $50 \%$ of all cases of central blindness [5], approximately reaching a prevalence of $3 \%$ among the general adult population [6]. In the United States, about $15 \%$ of people older than 80 years of age were estimated to have AMD on 2000, and this number is expected to rise in the next years reaching more than 2.95 million people with AMD in 2020 [7].

Numerous and heterogeneous pathological processes are likely to predispose an individual to AMD, which is considered an extremely complex, multifactorial disease. Aging represents its primary determinant, while environmental factors such as cigarette smoking $[8,9]$, dietary habits [10-12], and phototoxic exposure [13-15] contribute to significantly increase the risk of AMD occurrence, together with several gene polymorphisms [16-22]. In a populationbased twin study including both concordant/discordant and monozygotic/dizygotic sibling pairs, Seddon and coworkers have evaluated the relative contribution of heredity and environment to AMD etiology, concluding that heritability estimates for AMD are remarkable and range from $46 \%$ to $71 \%$ [23]. More recently, the same research group has indicated that individual genotypic susceptibility interacts with behavioral and nutritional factors in the etiology of AMD by means of various epigenetic mechanisms [24], further supporting the importance of the epigenetics into AMD investigations $[25,26]$. These data, along with findings of genome-wide association studies, emphasize the presence of an important rationale to practice the search for AMDrelated gene variants $[27,28]$, despite the unavoidable efforts required to plan genetic analyses of a complex disease with late onset. In particular, remarkable correlations were documented between common or rare immunological/inflammatory gene polymorphisms and AMD, unequivocally indicating the involvement of inflammation and immune-mediated processes (complement activation) in the pathogenesis of this disease [21, 29-32]. Thus, although AMD is not considered a classic inflammatory disease, immunocompetent cells, such as macrophages and lymphocytes, are present in the chorioretinal tissues affected by AMD [33, 34]. Moreover, peculiar signs of abnormalities/dysregulation of innate immune system are observed in eyes with AMD principally at the level of the complement pathway, including complement components C3a and C5a, C5 and C5b-9 terminal complement complex, complement regulators or inhibitors, that is, complement factor $\mathrm{H}(\mathrm{CFH})$, vitronectin and clusterin, complement receptor 1 (CR1, also called CD35), membrane cofactor protein (MCP, also called CD46), and decay accelerating factor (DAF, also called CD55), but also at the level of C-reactive protein (CRP) [18, 35-41]. In particular, activation products C3a, C5a, and C5b-9 are also systemically elevated in patients suffering from AMD [42-45]. In the course of AMD, several immunopathological phenomena occur within the NR-RPEBM-CC complex of the macular area, especially due to the pathophysiologic effects of complement system, which have a main role in the parainflammation of the aging retina [46-52]. Herein, we briefly review the literature on the involvements of inflammation in AMD, highlight the possible environmental, genetic, and/or epigenetic interactions, and discuss those therapeutic approaches potentially able to modulate inflammatory pathways and more directly translatable to the management of AMD patients.

\section{Parainflammation and Age-Related Macular Degeneration}

Parainflammation is defined as a condition of tissue adaptive response to noxious stress or malfunction, and it has features which are considered as intermediate between normal/basal and inflammatory/acute states. Although the physiological purposes of normal parainflammation are to preserve tissues homeostasis and to restore their functionality, when 
a tissue is exposed to stress and/or malfunction for a prolonged period, it is implicated in both initiation and progression of many human age-related disorders, such as AMD $[47,53]$. The risks of degenerative diseases, at least partially related to the pathophysiologic para-inflammatory response, are especially relevant in those tissues functionally dependent on nonproliferative cells and characterized by very high metabolism and other oxidative stress, such as the macular retina. In humans, the retina is a highly differentiated neuroectodermal tissue, in which an outer layer of photoreceptors, two layers of neuronal cells bodies, and two layers of synapses are present. The NR, together with RPE cells, forms the intraocular functional unit of the visual system. Like the components of central nervous system (brain and spinal cord) and several other tissues, retina also undergoes many pathophysiologic modifications with age. Because of cell and tissue damage/malfunction, mainly due to accumulative oxidative and metabolic changes in NR-RPE-BM-CC complex induced by reactive oxygen species (ROS), the vision sensitivity progressively declines during the aging process. In accordance with the "free radical theory of aging," originally expressed by Harman in 1956, age-related degeneration is basically caused by an imbalance between ROS-induced tissue damages and repair/remodelling processes [54]. This concept seems to be extremely important for human AMD; in fact, its main risk factors include increased age, smoking, augmented body mass index, phototoxicity and inflammation $[8-15,55]$, and all these factors augment ROS generation [14, 56-62]. Moreover, exactly the innate immune system, which plays a key role in tissue repair/remodeling processes, is also the same one that is more interconnected with AMD susceptibility and etiopathogenesis starting, respectively, from genotypic $[21,29-32]$ and phenotypic $[18,35-45]$ points of view. Particularly, the outer photoreceptor/RPE/MB complex, that is, the site of onset of the elementary AMD lesions (drusen), is considered more prone to oxidative stress because of both its proximity with the highly variable choroidal hemodynamics and its continuous exposition to photooxidation due to light stimuli $[13-15,63,64]$. In fact, unregulated blood flow may increase the fluctuations of tissue oxygen concentration, leading to elevated ROS generation by the mitochondria $[63,64]$. Likewise, photooxidation in photoreceptors is associated with complement activation [65], which can increase membrane attack complex formation, an important trigger of those apoptotic processes inducing nonlethal, retinal degeneration [66-68]. ROS augmentation can also trigger angiogenic signaling that has a crucial role in the occurrence of the more severe complication of AMD, that is, choroidal neovascularization (CNV) [69-72]. In other words, several factors, linked to AMD etiopathogenesis, lead to increased ROS generation and can mediate apoptosis and angiogenesis, which are more implicated in the atrophic and neovascular AMD forms, respectively [14, 46, 63-72]. Finally, the critical position of complement must be, once again, emphasized. In fact, dysregulation of complement pathways can lead to that autologous damage which, at the macular level, is manifested by the development of drusen. Starting from this rational (even if notional) point of view, the earliest hallmarks of AMD may act as foci of chronic inflammation $[49,52,73]$.

During the normal aging, in the NR, the number of neuronal and ganglion cells decreases, as also happens in the case of RPE cells which generally suffer the greatest losses in the macular and surrounding areas. Lipofuscin, the main aging-associated retinal end product, accumulates in the RPE cells with age, and its autofluorescent properties are routinely used in the clinical practice for the diagnostic imaging of various macular disorders. Another crucial age-related retinal change is the $\mathrm{BM}$ alteration, characterized by an increased thickness, accumulations of basal laminar deposits and/or drusen formation, and frequently accompanied by pigmentary irregularities due to RPE cell hypertrophy, hyperplasia, or atrophy. Usually, all these occurrences are more evident at the posterior pole in comparison with retinal periphery. In addition, both biochemical constitutions and biophysical properties of the BM modify with age, also influencing a further RPE cell dysfunction as well as noticeable CC disorders. Although the retina has been traditionally considered as an "immunologically privileged" tissue, at present it is known to have an endogenous immune system, actively coordinated by immunocompetent cells (microglia and dendritic cells), along with a rare population of perivascular macrophages; moreover, also RPE cells possess a variety of immunological functions. Retinal microglia and RPE cells, together with choroidal macrophages/dendritic cells, physiologically play an essential role in retinal homeostasis $[47,74-78]$. In the aging retina, all these elements represent important factors in both dealing with the retinal malfunctions and restoring retinal homeostasis or rebalancing the homeostatic points. Several sight-threatening retinal diseases have a higher prevalence among the elderly persons, but the most common of these is AMD that can be diagnosed in its early (Figures 2(a) and 2(b) [4]) or intermediate (Figures 3(a) and 3(b) [4]) drusen/RPE-atrophy/pigmentary forms, as well as in its advanced forms, that is, geographic atrophy and neovascular AMD (Figures 4(a)-4(d)) [3]. Even if the clinical pattern of the above-mentioned types of AMD significantly differs, low-grade/subclinical degree of inflammation (parainflammation) is implicated in every AMD forms, reaching a high level when maculopathy is complicated by CNV development [71]. In neuroretinal structure, para-inflammatory modifications are characterized by the breakdown of blood-retinal barrier, microglial activation, and subretinal migration, whereas, in the choroid they become evident with an increased number of $\mathrm{CD} 5^{+} \mathrm{CRIg}^{+}$macrophages, morphologic abnormalities of melanocytes, tissue's thickening, and fibrosis. At the retinal/choroidal interface, these AMD-related changes are particularly manifested by complement activation in RPE$\mathrm{BM}$ cells and microglia accumulation in subretinal space $[47,48,71]$. Insightful knowledge on the mechanisms of retinal parainflammation, as well as of complement dysregulation, is fundamental to comprehensively understand the pathogenesis of AMD and to develop better curative therapeutic strategies for the different forms of this harmful disease. 


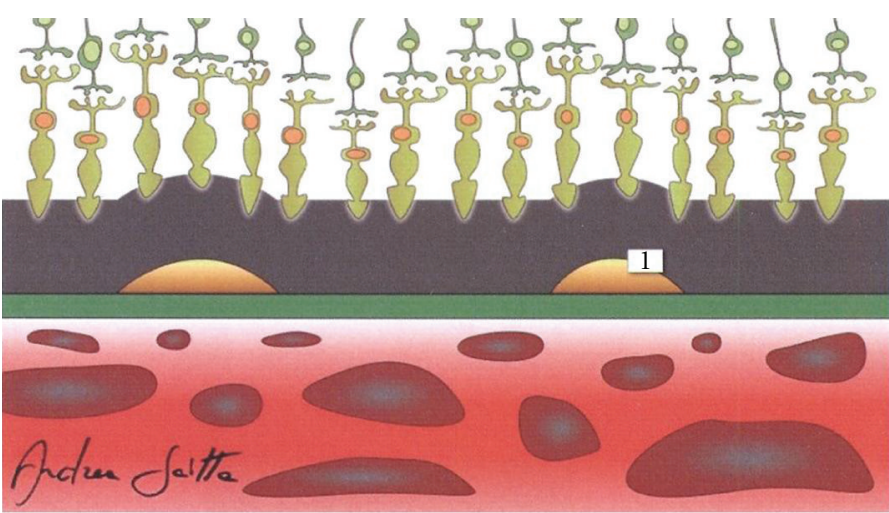

(a)

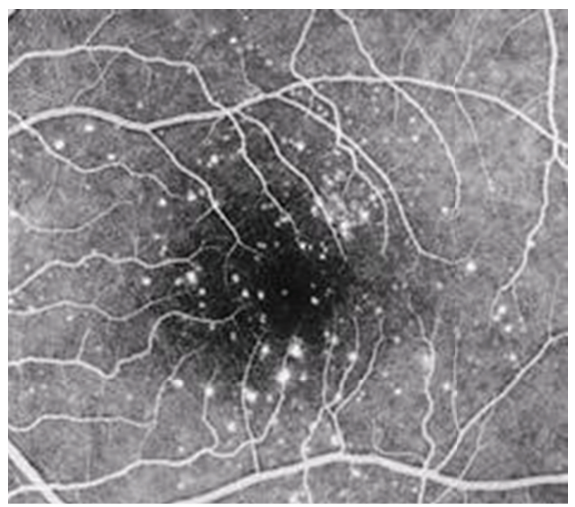

(b)

FiguRE 2: Early age-related macular degeneration. (a) Schematic cross-sectional illustration of the macula with an early stage of the disease ((1) drusen). (b) Fluorescein angiography of the macula affected by an early form of the disease (nonconfluent hard drusen); in this eye, the best best-correct visual acuity was 20/20 (Snellen equivalent) (extracted and modified from [4]).

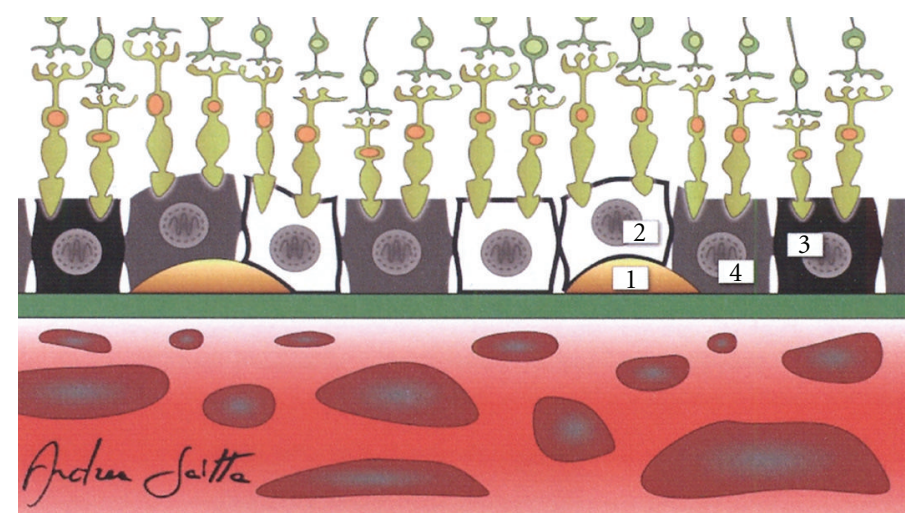

(a)

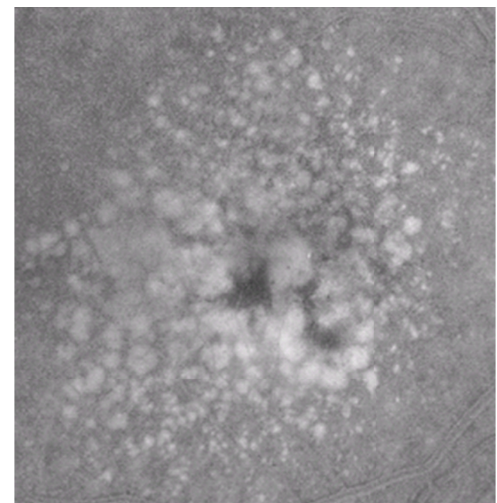

(b)

Figure 3: Intermediate age-related macular degeneration. (a) Schematic cross-sectional illustration of the macula with an intermediate stage of the disease ((1) drusen; (2) atrophy of a cell of the retinal pigment epithelium; (3) hypertrophy or hyperplasia of a cell of the retinal pigment epithelium; (4) a normal cell of the retinal pigment epithelium). (b) Fluorescein angiography of the macula affected by an intermediate form of the disease (confluent soft drusen and pigmentary irregularities); in this eye, the best best-correct visual acuity was 20/50 (Snellen equivalent) (extracted and modified from [4]).

\section{Complement System and Age-Related Macular Degeneration}

Complement system consists of over 40 proteins and regulators which are detectable in the blood circulation. It plays a key role in host defense against pathogens, adaptive immune responses, removal of the immune complexes and apoptotic cells [79]. In humans, three complement-mediated pathways complementarily act, and each of them is characterized by a specific trigger as follows:

(i) antibody-antigen complex for the classical pathway;

(ii) binding to host cell or pathogen surface for the alternative pathway;

(iii) polysaccharides on microbial surfaces for the lectin pathway.

Dysregulation and/or dysfunction of the complement pathways can result in various critical autologous damages, with consequent pathogenetic implications in a wide spectrum of diseases [52]. Both pathogenesis and progression of AMD represent complex events, in which complement system is directly or indirectly implicated. Pathobiologic studies have identified numerous complement proteins inside drusen (i.e., the elementary clinical lesions identifiable in the macula of AMD patients), and genetic analyses have discovered the existence of common or rare polymorphisms in several complement-related genes that significantly increase or reduce the risk for AMD late in life [49]. In fact, the phenotypic features of drusen (i.e., clinical pattern and time of onset) and the genotypic individual background for AMD seem to be mutually and closely intersected with each other, figuratively sharing, as lowest common denominator, the local dysregulation of the complement system in the NR-RPE-BM-CC complex due to acquired and/or inherited risk factors. In particular, the development of AMD-related drusen occurs between the basal surface of 


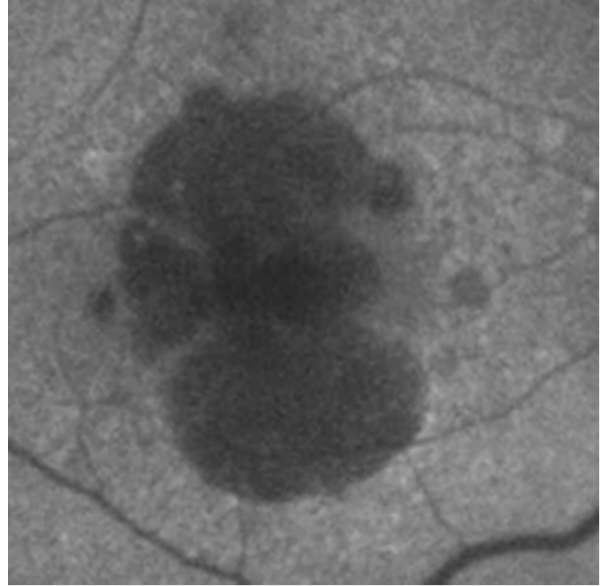

(a)

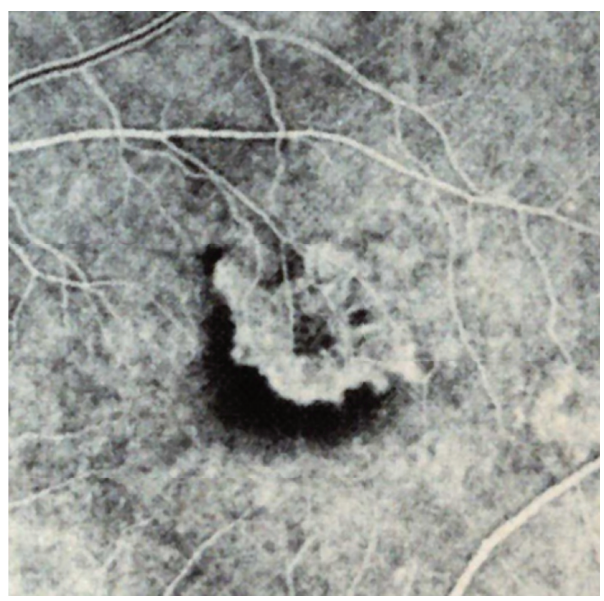

(c)

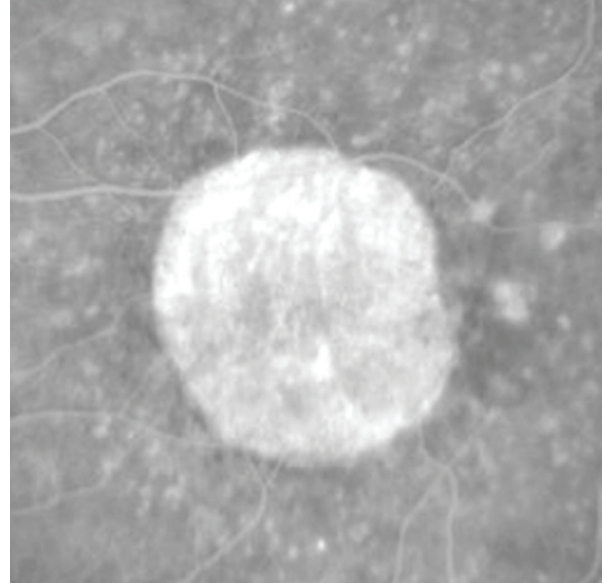

(b)

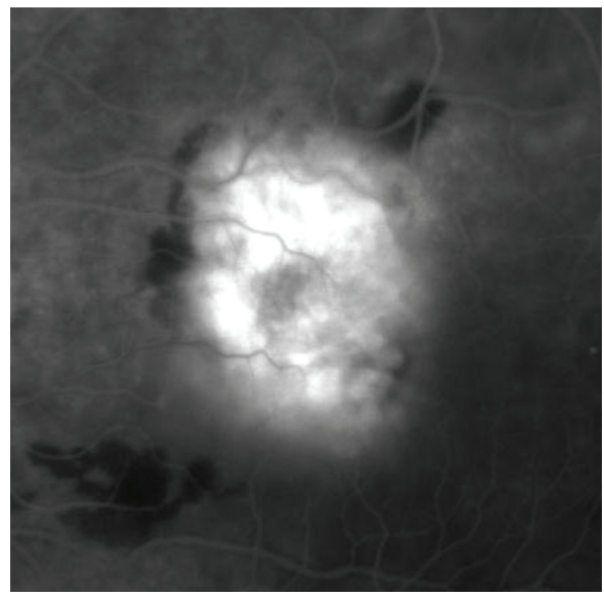

(d)

FIGURE 4: Advanced forms of age-related macular degeneration. (a) Autofluorescent retinography and (b) fluorescein angiography of two different cases of severe central geographic atrophy; in these eyes, the best-correct visual acuities were, respectively, 20/125 and 20/160 (Snellen equivalent). (c) Early and (d) late fluorescein angiograms of two different cases of subfoveal choroidal neovascularization; in both these eyes, the best-correct visual acuity was 20/200 (Snellen equivalent).

RPE and the BM, a single-stratified extracellular matrix in contact with CC (Figures 2(a) and 3(a) [4]) [80]. Since the mid 1990s, increasing experimental and clinical evidences clearly indicate that a lot of complement-related molecules, such as complement activators, complement components, and complement regulatory proteins, represent substantial constituents of the drusen $[35,36,65,66,73,81-93]$. Starting from the beginning of the 2000s, the more and more exact identification of their compositional profile has been essential to create the basis for a new paradigm of AMD pathogenesis, in which macular and perimacular drusen should be considered as the earliest diagnosable byproducts of chronic local para-inflammatory phenomena at BM level. According to this model of AMD occurrence and progression, parainflammation of retinochoroidal tissues, accompanied by complement activation, immune-mediated processes, and bystander cell lysis, becomes the most crucial aspect of this neurodegenerative maculopathy [47-52, 73, 85, 94].
In the course of the past few years, a definitive support for the "immuno-inflammatory" model of AMD pathogenesis has been evidenced by the clinical-genetic findings of numerous studies, which revealed highly significant correlations between AMD and polymorphisms of genes encoding for several molecules directly involved in the activities of the complement alternative pathway. Of these genes/loci, the most studied ones are:

(i) complement factor $\mathrm{H}(\mathrm{CFH})$ [16-18, 95-99],

(ii) complement component 3 (C3) [100-103],

(iii) complement factor I (CFI) [104, 105],

(iv) complement factor B (CFB) [19, 106, 107],

(v) complement component 2 (C2) [19, 106, 107],

(vi) CFH-related genes (CFHR) type 1-5 [108-110].

Even if some of these relationships between these genes/loci and AMD are incompletely understood, their 
comprehensive consideration indicates, once again, that complement-related polymorphic alleles are able to increase (CFH, C3, CFI, and CFHR-2-4-5) or reduce (CFB, C2, and CFHR-1-3) AMD risk, representing a central key point on which the evidences of the high heritability of AMD are based $[23,106,111]$. Then again, genetic susceptibility to AMD is a very multifaceted issue that also includes several other immunological/inflammatory aspects, either just indirectly linked or not linked to complement system such as, for example:

(i) interactions between C-reactive protein (CRP) and $\mathrm{Y} 402 \mathrm{H}$ variant of $\mathrm{CFH}$ gene (rs1061170), a very common single nucleotide polymorphism (SNP) located within the chromosome $1 \mathrm{q} 32$ region and unequivocally identified in association with AMD among multiple study populations_-providing for the first time a logical basis by which to assess the disease's risk in over $50 \%$ of affected individuals $[49,50,52,112]$;

(ii) potential synergisms between the above-mentioned SNPs in genes/loci encoding for factors or components of the alternative complement pathway and some noncomplement-related genes, located on the chromosome 10q26 region and extensively described as strongly implicated in AMD pathogenesis, that is, the rs10490924 SNP of the age-related maculopathy susceptibility 2 (ARMS2), and the rs11200638 SNP of the high-temperature requirement factor $\mathrm{A}$ of serine peptidase 1 (HTRA1) [21, 22, 26, 49, 111].

CRP is a biomarker of acute-phase inflammation. It plays an essential role in the innate immune response to tissue injury and/or infection. Because CRP induces complement activation via the alternative pathway, it is plausible that CRP may have a direct responsibility in AMD pathogenesis by causing macular damages via complementmediated mechanisms, as also happens in the case of $\mathrm{CFH}$ $[46,50,71,113,114]$. In fact, although several facets of the CFH-CRP interaction are not yet well defined [115], several findings have indicated that in carriers of the polymorphic $\mathrm{H} 402$ variant of $\mathrm{CFH}$ gene a lower affinity for CRP exists in respect of the individuals with the Y402 protein $[92,116$, 117]. Moreover, a more recent study has confirmed that native CRP-CFH interaction is evident at high plasma CRP concentrations (as happens during the acute-phase response, i.e., when the $\mathrm{H} 402$ protein inadequately binds to CRP) [118], and also a large meta-analysis has documented that serum levels of CRP $>3 \mathrm{mg} / \mathrm{L}$ are related to a double AMD risk in comparison with CRP concentrations <1 mg/L [119]. Starting from these latter results, it is not surprising that homozygous $\mathrm{CFH}-\mathrm{Y} 402 \mathrm{H}$ polymorphic genotype, together with elevated serum/plasma CRP levels, leads to a very high risk of both $\mathrm{AMD}$ and its progression (with odds ratios of 19.3 and 6.8 , resp.) [120], even if the CRP elevation is not related to any variant of the CRP gene and no polymorphism in this gene is directly associated with AMD $[121,122]$. As well, at the levels of RPE and choroid of CFH-H402 homozygous carriers, a greater amount of
CRP was detected in comparison with that found in Y402 homozygotes, but there was no significant difference in $\mathrm{CFH}$ protein concentrations among individuals with diverse Y402H genotypes. This lack of local CRP expression indicates that CRP is present in the posterior segment of the eye as a consequence of deposition through chronic low-grade local inflammation [91].

Based on early genome-wide linkage analyses, which have established that the 10q26 locus is closely associated with AMD [123-126], several clinical-genetic studies, specifically focused on this chromosomal region, discovered two major hereditary predisposing factors for AMD: the ARMS2 [127, 128] and the HTRA1 genes [129, 130]. At present, ARMS2 locus is considered a noncomplement-related gene because its potential role in the inflammatory process, if any, remains to be clarified [49]. In fact, although rs10490924-ARMS2 mRNA is detected in the human retina, both prevalent expression and cellular location of its putative protein are still under debate, having been initially observed in the mitochondrial outer membrane [131], and later in the cytosol and extracellular compartment [132, 133]. In any case, it seems extremely unlikely that deficiency of ARMS2related protein could be a direct pathogenic mechanism responsible for AMD [134]. Also HTRA1 locus, encoding for a secreted protein belonging to the high-temperature requirement A family of serine proteases, can be still labeled as noncomplement-related gene [49]. However, because some molecules involved in the complement activities (i.e., clusterin, vitronectin, and fibromodulin) represent specific substrates for HTRA1 serine protease, an implication of HTRA1 in complement system has been notionally indicated [135]. The initial investigations documented the correlation between the rs11200638 promoter variant of the HTRA1 gene and an increased expression of its protein [129, 130], whereas other studies have not replicated these outcomes [131, 136]. Nevertheless, more recent reports showed that HTRA1 mRNA expression is higher in cultured RPE cells homozygous for the HTRA1 allele related to AMD risk, also supporting the perception that HTRA1 could be one of the causal genes in AMD patients [135, 137, 138].

In consideration of the heterogeneous gene-gene relationships between the major risk variants of the $\mathrm{CFH}$, ARMS2, and HTRA1 loci, several Authors have emphasized the consistent possibility of an independent multiplicative joint effect in AMD, also taking into account that each of them should be contextualized within geneenvironment interactions and epigenetic aspects [22-25, 49, 139, 140]. Exclusively limiting the focus on those wellrecognized SNPs which confer increased or decreased risk of inflammation (i.e., CFH, CX3CR1, IL-8, and TLR3 and 4), and voluntarily ignoring the other, suspected or ascertained, AMD-related gene variants (i.e., APOE, ABCR, LIPC, TIMP3, PON1, ERCC6, ELOVL4, fibulin-5, hemicentin-1, SERPING1, VLDLR, LRP6, VEGF, and KDR), the etiopathogenetic scenario of AMD is exactly that of a complex/polygenic disease characterized by (i) multiple clinical phenotypes with non-Mendelian transmission; (ii) environmental effects; (iii) increased incidence with age; (iv) specific susceptibility genes with variant alleles (Table 1) [20, 
TABLE 1: Main AMD-susceptibility genetic loci.

\begin{tabular}{lcc}
\hline Locus & Role in immunoinflammatory pathways & Possibility of AMD-risk elevation \\
\hline CFH & Yes (complement system) & High (in carriers of polymorphic allele) \\
ARMS2 & Not clarified & High (in carriers of polymorphic allele) \\
HTRA1 & Possible (complement system) & High (in carriers of polymorphic allele) \\
CFB & Yes (complement system) & Intermediate (in carriers of wild allele) \\
C2 & Yes (complement system) & Intermediate (in carriers of wild allele) \\
C3 & Yes (complement system) & Intermediate (in carriers of polymorphic allele) \\
CFI & Yes (complement system) & Low (in carriers of polymorphic allele) \\
TIMP3 & Yes (immunity in extracellular matrix) & Low (in carriers of polymorphic allele) \\
LIPC & Not clarified & Low (in carriers of polymorphic allele) \\
ABCR & No & Low (in carriers of polymorphic allele) \\
APOE & No & Low (in carriers of polymorphic allele) \\
\hline
\end{tabular}

Legend: CFH: complement factor H; ARMS2: age-related maculopathy susceptibility 2; HTRA1: high-temperature requirement factor A of serine peptidase 1; CFB: complement factor B; C2: complement component 2; C3: complement component 3; CFI: complement factor I; TIMP3: tissue inhibitor of metalloproteinases 3; LIPC: hepatic lipase gene; ABCR: ATP-binding cassette transporter; APOE: apolipoprotein E.

$22,25,26,29,46,140-162]$. The next section of this paper focuses on those immunological/inflammatory topics more directly translatable to improve the therapeutic strategies against AMD and, in particular, against its neovascular form, often responsible for the cases of most severe visual loss.

\section{Agents Directed against the Immune Response and Age-Related Macular Degeneration}

The responses of human immune system are necessary to defend our organism against several diseases, external antigens, invading microorganisms and/or acute tissue injuries. However, the contribution of the immune system in the occurrence of chronic age-related pathologic conditions has not been yet fully understood. In the course of the normal aging, as well as during chronic diseases, low-grade tissue stress (caused by noninfectious insults) may be related to subclinical damages resulting in the release of endogenous molecules, collectively called "alarmins", that activate immunocompetent cells capable to support both innate and acquired immunity. In fact, they recruit and/or trigger receptor-expressing cells of the innate immune system, such as dendritic cells and macrophages, and consequently can also promote adaptive immunity in either direct or indirect manner [47]. To restore tissue homeostasis, by means of a mounting localized para-inflammatory response, immune system must be able to early identify such minimal biopathological changes in each specific district. Conversely, dysregulation or dysfunction of the immune system in chronically facing low-grade stress conditions may lead to manifest pathologies.

The retina, like the brain, is a high-metabolism tissue and is sensitive to noxious microenvironmental stimulations; however, unlike the brain, it is constantly exposed to the light, which can produce loads of photooxidized materials. Light-related stress and other oxidative damages increase in retinal tissue with the aging, as does the para-inflammatory response. In this view, although AMD is not a classic inflammatory disease, innate immunity and autoimmune components (i.e., complement factors, chemokines, cytokines, macrophages, and ocular microglia) have a reliable role in both pathogenesis and progression of AMD [47, 49, 163]. During the last two decades, directly or indirectly targeting these specific molecules/components, implicated in the immunoinflammatory pathways, has been assessed in the attempt to improve the therapeutic management of patients affected by the different clinical forms of AMD (Figures 2-4).

Since the mid 2000s, the Age-Related Eye Disease Study (AREDS, a large multicenter randomized clinical trial evaluating the long-term effects of high-dose antioxidant nutritional supplements on the incidence and progression of AMD and cataract) has documented a significantly lower incidence of advanced AMD in patients with drusen maculopathy treated with appropriate dosages of antioxidants than in a placebo group [164-169]. Also other studies and evidences indicate the opportunity to indirectly counteract para-inflammatory changes minimizing the retinal oxidative stresses in AMD patients [11, 13-15, 170, 171]. In particular, oral lutein intake results in beneficial effects on various visual function tests, and recent findings show that it is able to influence immune/inflammatory responses, not only diminishing the manifestation of various ocular inflammation models, but also suppressing NF kappa-B activation and/or inhibiting the expression of iNOS and COX-2 [48, 171].

On the other hand, during the last few years, numerous trials have been started to verify the therapeutic effects of various drugs aimed to directly downgrade the retinochoroidal immune response in AMD patients. In the next future, the outcomes of these ongoing clinical studies (156 studies found at http://clinicaltrials.gov/ searching, on June, 26 2012, with the keywords "age-related macular degeneration" and "anti-inflammatory") together with the already reported findings $[163,172-175]$ will be able to provide a more exact delineation of the role of the agents directed against the immune response in therapeutic recommendations for AMD patients [165-168, 176-186]. The majority of these 
interventional trials are conducted on patients affected by neovascular AMD, employing corticosteroids (i.e., dexamethasone and triamcinolone acetonide), nonsteroidal anti-inflammatory drugs (i.e., low-dose acetylsalicylic acid, bromfenac, diclofenac, and nepafenac), immunosuppressive agents (i.e., methotrexate and rapamycin), and biologics (i.e., anti-TNF- $\alpha$ agents such as infliximab and adalimumab, IL-2-receptor antagonists such as daclizumab, and complement inhibitors/regulators such as ARC1905, TNX-234, eculizumab, and POT-4), with the exception of rapamycin which has been also evaluated in cases of geographic atrophy secondary to AMD $[163,187]$.

The pathogenetic scenario that gives rise to the first RPE-BM-CC alterations in AMD is extremely complex. It includes a variety of predisposing genetic backgrounds, which can take effect on an heterogeneous plethora of parainflammatory causative factors: cigarette smoking, phototoxic oxidative exposure, dietary habits, alterations of iron and lipid homeostasis, buildup of advanced glycation endproducts, microbial infection, lipofuscin and beta-amyloid toxicity, excessive immune-complex generation, choroidal hemodynamic insufficiency and ischemia, phagocytic overload, and/or RPE autophagy [49]. However, regardless of what are the conditions that can initially trigger the macular degenerative pattern in each individual AMD patient, it is indisputable that the decisive downstream consequences are the deposition and/or sequestration of both cellular and acellular debris at sub-RPE level. In the course of the normal human aging, mid- or long-term malfunctions in the tissue processing of these debris can be sufficient to locally generate abnormal para-inflammatory signal with a consequent aberrant activation of the complement system. This macular status would most likely result in persistent complement attack, further sub-RPE deposits, continuous formation of drusen, bystander injury to neighboring cells and, finally, irreversible photoreceptor degeneration and/or deconstruction (especially in those lots of adult or elder individuals who are more genetically susceptible to AMD for the presence of polymorphisms influencing the immuneinflammatory pathways and, in particular, the alternative complement-modulating activity) $[25,47,49]$. Starting from this rationale, our current knowledge regarding the role of both inflammation and complement systems in AMD should be refined to the point where it can be more easily translated in an innovative enhancement of AMD treatments, by means of either comparative randomized clinical trials or interventional pilot studies or biogenetic therapeutic researches.

\section{Final Remarks}

In the recent years, a substantial amount of evidences and/or arguments document the crucial responsibility of immuneinflammatory processes in the pathogenesis of AMD [3, 47$52,71,188]$, clearly indicating the importance not only of specific complement-modulation agents, but also of nonspecific anti-inflammatory drugs, as adjunctive therapies for both non neovascular AMD (conventionally treated with AREDS formula and lutein) $[163,165-171]$ and, most of all, neovascular AMD (routinely treated with intravitreal administration of drugs acting against vascular endothelial growth factor (anti-VEGF) and/or with photodynamic therapy with verteporfin (PDT-V)) [163, 172-186, 189-194]. The fact that para-inflammatory dysregulation is already present in the early stage of AMD may notionally support the preventive employment of agents directed against the immune-inflammatory response in combination with highdose nutritional supplements (particularly in those patients with a disabling form of maculopathy in one eye, younger than 65 years, and/or carrier of significant genetic susceptibility to AMD) [30, 164-171]. On the other hand, the existence of variable mid-term responsiveness of $\mathrm{CNV}$ to either anti-VEGF or PDT-V regimen (often resulting in elevated risks of legal blindness, high societal costs and expensive economic burden) practically recommends, above all in patients with advanced AMD in one eye, the adjunctive utilization of drugs directed against the immuneinflammatory response in combination with anti-VEGF injections and/or PDT-V [114, 171, 176-179, 183-185, 195217].

Returning to focus on the above-mentioned translational concepts about the opportunity of pharmacologic modulation toward the immune-inflammatory pathways in AMD, a comprehensive approach is warranted to verify the chances of a prompt application of this curative modality in the clinical setting. In theory, to modulate the complement attack and minimize the local parainflammation in AMD patients who carry one or more complement-related gene polymorphisms predisposing to the disease, the most specific approach would augment the retinochoroidal bioavailability of the native/protective form of those complement factors or components responsible for the genetic susceptibility to AMD [218-220]. Adhering to this work hypothesis, a variety of delivery systems (i.e., gene transfer, cell-based therapies, organ (liver) transplantation, systemic or intraocular injections) can be envisioned to slow or arrest AMD by reasserting control over the complement system and, in particular, over its alternative pathway. If this biogenetic "augmentation" concept will be applicable also in the clinical AMD patterns, new complement-modulation therapeutics could be added to those several drugs directed against the immune-inflammatory response and already being tested on humans [49, 163]. However, at the moment, pending the concrete applicative possibilities of these biogenetic and/or pharmacologic complement-targeted treatments, open-label clinical trials are recommend, especially in patients with neovascular AMD, to better evaluate the therapeutic anti$\mathrm{CNV}$ rationale in combining intravitreal corticosteroids either with the conventional anti-VEGF regimens or with anti-VEGF plus PDT-V customized protocols. In this view of good postmarketing study practice, as additional antiCNV treatment, a promising anti-inflammatory strategy is that which involves the use of drug delivery systems (i.e., nonbiodegradable insert or biodegradable implant), able to provide a sustained release of intravitreal corticosteroids (fluocinolone acetonide or dexamethasone) for several months [221, 222]. In fact, taking into account both that immunoinflammatory phenomena are very active during 
the occurrence of an AMD-related CNV [71, 223], and that corticosteroids act upstream in immunoinflammatory cascades with consequent inhibition of the alternativeamplification of complement pathway [224, 225], and that a prolonged pharmacologic action represents an important parameter for the final efficacy of any therapy against neovascular AMD [176-180], the above-described intraocular devices, already approved for the treatment of peculiar forms of macular edema and of noninfectious posterior uveitis $[221,222]$, could represent a rational adjunctive therapeutic approach for patients with neovascular AMD undergoing repeated intravitreal injections of anti-VEGF drug.

\section{References}

[1] J. Ambati, B. K. Ambati, S. H. Yoo, S. Ianchulev, and A. P. Adamis, "Age-related macular degeneration: etiology, pathogenesis, and therapeutic strategies," Survey of Ophthalmology, vol. 48, no. 3, pp. 257-293, 2003.

[2] P. T. V. M. De Jong, "Age-related macular degeneration," The New England Journal of Medicine, vol. 355, no. 14, pp. 14741485, 2006.

[3] H. R. Coleman, C. C. Chan, F. L. Ferris, and E. Y. Chew, "Agerelated macular degeneration," The Lancet, vol. 372, no. 9652, pp. 1835-1845, 2008.

[4] A. Saitta, Anti-angiogenic drugs in the treatment of the neovascular age-related macular degeneration [M.S. thesis], The School of Medicine of the University of Ferrara, 2009.

[5] S. Resnikoff, D. Pascolini, D. Etya'ale et al., "Global data on visual impairment in the year 2002," Bulletin of the World Health Organization, vol. 82, no. 11, pp. 844-851, 2004.

[6] R. Klein, K. J. Cruickshanks, S. D. Nash et al., "The prevalence of age-related macular degeneration and associated risk factors," Archives of Ophthalmology, vol. 128, no. 6, pp. 750758, 2010.

[7] D. S. Friedman, B. J. O’Colmain, B. Muñoz et al., "Prevalence of age-related macular degeneration in the United States," Archives of Ophthalmology, vol. 122, no. 4, pp. 564-572, 2004.

[8] J. Thornton, R. Edwards, P. Mitchell, R. A. Harrison, I. Buchan, and S. P. Kelly, "Smoking and age-related macular degeneration: a review of association," Eye, vol. 19, no. 9, pp. 935-944, 2005.

[9] U. Chakravarthy, C. Augood, G. C. Bentham et al., "Cigarette smoking and age-related macular degeneration in the EUREYE Study," Ophthalmology, vol. 114, no. 6, pp. 1157-1163, 2007.

[10] S. Kaushik, J. J. Wang, V. Flood et al., "Dietary glycemic index and the risk of age-related macular degeneration," American Journal of Clinical Nutrition, vol. 88, no. 4, pp. 1104-1110, 2008.

[11] J. S. L. Tan, J. J. Wang, V. Flood, E. Rochtchina, W. Smith, and P. Mitchell, "Dietary antioxidants and the long-term incidence of age-related macular degeneration: the Blue Mountains Eye Study," Ophthalmology, vol. 115, no. 2, pp. 334-341, 2008.

[12] A. U. Kishan, B. S. Modjtahedi, E. N. Martins, S. P. Modjtahedi, and L. S. Morse, "Lipids and age-related macular degeneration," Survey of Ophthalmology, vol. 56, no. 3, pp. 195-213, 2011.

[13] J. Wu, S. Seregard, and P. V. Algvere, "Photochemical damage of the retina," Survey of Ophthalmology, vol. 51, no. 5, pp. 461-481, 2006.
[14] A. Wenzel, C. Grimm, M. Samardzija, and C. E. Remé, "Molecular mechanisms of light-induced photoreceptor apoptosis and neuroprotection for retinal degeneration," Progress in Retinal and Eye Research, vol. 24, no. 2, pp. 275306, 2005.

[15] P. V. Algvere, J. Marshall, and S. Seregard, "Age-related maculopathy and the impact of blue light hazard," Acta Ophthalmologica Scandinavica, vol. 84, no. 1, pp. 4-15, 2006.

[16] R. J. Klein, C. Zeiss, E. Y. Chew et al., "Complement factor H polymorphism in age-related macular degeneration," Science, vol. 308, no. 5720, pp. 385-389, 2005.

[17] J. L. Haines, M. A. Hauser, S. Schmidt et al., "Complement factor $\mathrm{H}$ variant increases the risk of age-related macular degeneration," Science, vol. 308, no. 5720, pp. 419-421, 2005.

[18] G. S. Hageman, D. H. Anderson, L. V. Johnson et al., "A common haplotype in the complement regulatory gene factor $\mathrm{H}(\mathrm{HF} 1 / \mathrm{CFH})$ predisposes individuals to age-related macular degeneration," Proceedings of the National Academy of Sciences of the United States of America, vol. 102, no. 20, pp. 7227-7232, 2005.

[19] K. L. Spencer, M. A. Hauser, L. M. Olson et al., "Protective effect of complement factor B and complement component 2 variants in age-related macular degeneration," Human Molecular Genetics, vol. 16, no. 16, pp. 1986-1992, 2007.

[20] J. Tuo, B. C. Smith, C. M. Bojanowski et al., "The involvement of sequence variation and expression of CX3CR1 in the pathogenesis of age-related macular degeneration," The FASEB Journal, vol. 18, no. 11, pp. 1297-1299, 2004.

[21] J. Bergeron-Sawitzke, B. Gold, A. Olsh et al., "Multilocus analysis of age-related macular degeneration," European Journal of Human Genetics, vol. 17, no. 9, pp. 1190-1199, 2009.

[22] N. Leveziel, J. Tilleul, N. Puche et al., "Genetic factors associated with age-related macular degeneration," Ophthalmologica, vol. 226, no. 3, pp. 87-102, 2011.

[23] J. M. Seddon, J. Cote, W. F. Page, S. H. Aggen, and M. C. Neale, "The US twin study of age-related macular degeneration: relative roles of genetic and environmental influences," Archives of Ophthalmology, vol. 123, no. 3, pp. 321-327, 2005.

[24] J. M. Seddon, R. Reynolds, H. R. Shah, and B. Rosner, "Smoking, dietary betaine, methionine, and vitamin D in monozygotic twins with discordant macular degeneration: epigenetic implications," Ophthalmology, vol. 118, no. 7, pp. 1386-1394, 2011.

[25] L. M. Hjelmeland, "Dark matters in AMD genetics: epigenetics and stochasticity," Investigative Ophthalmology and Visual Science, vol. 52, no. 3, pp. 1622-1631, 2011.

[26] J. Tuo, S. Grob, K. Zhang, and C. C. Chan, "Genetics of immunological and inflammatory components in agerelated macular degeneration," Ocular Immunology and Inflammation, vol. 20, no. 1, pp. 27-36, 2012.

[27] H. Y. Rienhoff, "Genomewide association studies and assessment of risk of disease," The New England Journal of Medicine, vol. 363 , no. 21 , p. $2077,2010$.

[28] I. Peter and J. M. Seddon, "Genetic epidemiology: successes and challenges of genome-wide association studies using the example of age-related macular degeneration," American Journal of Ophthalmology, vol. 150, no. 4, pp. 450-452, 2010.

[29] P. J. Francis, S. C. Hamon, J. Ott, R. G. Weleber, and M. L. Klein, "Polymorphisms in C2, CFB and C3 are associated with progression to advanced age related macular degeneration associated with visual loss," Journal of Medical Genetics, vol. 46, no. 5, pp. 300-307, 2009. 
[30] F. Ricci, S. Zampatti, F. D’Abbruzzi et al., “Typing of ARMS2 and $\mathrm{CFH}$ in age-related macular degeneration: case-control study and assessment of frequency in the Italian population," Archives of Ophthalmology, vol. 127, no. 10, pp. 1368-1372, 2009.

[31] E. Ryu, B. L. Fridley, N. Tosakulwong, K. R. Bailey, and A. O. Edwards, "Genome-wide association analyses of genetic, phenotypic, and environmental risks in the age-related eye disease study," Molecular Vision, vol. 16, pp. 2811-2821, 2010.

[32] K. J. Meyer, L. K. Davis, E. I. Schindler et al., "Genomewide analysis of copy number variants in age-related macular degeneration," Human Genetics, vol. 129, no. 1, pp. 91-100, 2011.

[33] P. L. Penfold, M. C. Killingsworth, and S. H. Sarks, "Senile macular degeneration: the involvement of immunocompetent cells," Graefe's Archive for Clinical and Experimental Ophthalmology, vol. 223, no. 2, pp. 69-76, 1985.

[34] P. F. Lopez, H. E. Grossniklaus, H. M. Lambert et al., "Pathologic features of surgically excised subretinal neovascular membranes in age-related macular degeneration," American Journal of Ophthalmology, vol. 112, no. 6, pp. 647-656, 1991.

[35] R. F. Mullins, S. R. Russell, D. H. Anderson, and G. S. Hageman, "Drusen associated with aging and age-related macular degeneration contain proteins common to extracellular deposits associated with atherosclerosis, elastosis, amyloidosis, and dense deposit disease," The FASEB Journal, vol. 14, no. 7, pp. 835-846, 2000.

[36] L. V. Johnson, S. Ozaki, M. K. Staples, P. A. Erickson, and D. H. Anderson, "A potential role for immune complex pathogenesis in drusen formation," Experimental Eye Research, vol. 70, no. 4, pp. 441-449, 2000.

[37] M. Nozaki, B. J. Raisler, E. Sakurai et al., "Drusen complement components $\mathrm{C} 3 \mathrm{a}$ and $\mathrm{C} 5 \mathrm{a}$ promote choroidal neovascularization," Proceedings of the National Academy of Sciences of the United States of America, vol. 103, no. 7, pp. 2328-2333, 2006.

[38] A. Lommatzsch, P. Hermans, B. Weber, and D. Pauleikhoff, "Complement factor $\mathrm{H}$ variant $\mathrm{Y} 402 \mathrm{H}$ and basal laminar deposits in exudative age-related macular degeneration," Graefe's Archive for Clinical and Experimental Ophthalmology, vol. 245, no. 11, pp. 1713-1716, 2007.

[39] A. Lommatzsch, P. Hermans, K. D. Müller, N. Bornfeld, A. C. Bird, and D. Pauleikhoff, "Are low inflammatory reactions involved in exudative age-related macular degeneration?" Graefe's Archive for Clinical and Experimental Ophthalmology, vol. 246, no. 6, pp. 803-810, 2008.

[40] I. A. Bhutto, T. Baba, C. Merges, V. Juriasinghani, D. S. McLeod, and G. A. Lutty, "C-reactive protein and complement factor $\mathrm{H}$ in aged human eyes and eyes with age-related macular degeneration," British Journal of Ophthalmology, vol. 95, no. 9, pp. 1323-1330, 2011.

[41] A. L. Fett, M. M. Hermann, P. S. Muether, B. Kirchhof, and S. Fauser, "Immunohistochemical localization of complement regulatory proteins in the human retina," Histology and Histopathology, vol. 27, no. 3, pp. 357-364, 2012.

[42] S. Sivaprasad, T. Adewoyin, T. A. Bailey et al., "Estimation of systemic complement C3 activity in age-related macular degeneration," Archives of Ophthalmology, vol. 125, no. 4, pp. 515-519, 2007.

[43] H. P. N. Scholl, P. C. Issa, M. Walier et al., "Systemic complement activation in age-related macular degeneration," PLoS ONE, vol. 3, no. 7, Article ID e2593, 2008.
[44] A. MacHalińska, V. Dziedziejko, K. Mozolewska-Piotrowska, D. Karczewicz, B. Wiszniewska, and B. MacHaliński, "Elevated plasma levels of c3a complement compound in the exudative form of age-related macular degeneration," Ophthalmic Research, vol. 42, no. 1, pp. 54-59, 2009.

[45] R. Reynolds, M. E. Hartnett, J. P. Atkinson, P. C. Giclas, B. Rosner, and J. M. Seddon, "Plasma complement components and activation fragments: associations with age-related macular degeneration genotypes and phenotypes," Investigative Ophthalmology and Visual Science, vol. 50, no. 12, pp. 58185827, 2009.

[46] X. Ding, M. Patel, and C. C. Chan, "Molecular pathology of age-related macular degeneration," Progress in Retinal and Eye Research, vol. 28, no. 1, pp. 1-18, 2009.

[47] H. Xu, M. Chen, and J. V. Forrester, "Para-inflammation in the aging retina," Progress in Retinal and Eye Research, vol. 28, no. 5, pp. 348-368, 2009.

[48] M. Chen, J. V. Forrester, and H. Xu, "Dysregulation in retinal para-inflammation and age-related retinal degeneration in CCL2 or CCR2 deficient mice," PLoS ONE, vol. 6, no. 8, Article ID e22818, 2011.

[49] D. H. Anderson, M. J. Radeke, N. B. Gallo et al., "The pivotal role of the complement system in aging and agerelated macular degeneration: hypothesis re-visited," Progress in Retinal and Eye Research, vol. 29, no. 2, pp. 95-112, 2010.

[50] L. A. Donoso, T. Vrabec, and H. Kuivaniemi, "The role of complement factor $\mathrm{H}$ in age-related macular degeneration: a review," Survey of Ophthalmology, vol. 55, no. 3, pp. 227-246, 2010.

[51] L. V. Johnson, D. L. Forest, C. D. Banna et al., "Cell culture model that mimics drusen formation and triggers complement activation associated with age-related macular degeneration," Proceedings of the National Academy of Sciences of USA, vol. 108, no. 45, pp. 18277-18282, 2011.

[52] S. Khandhadia, V. Cipriani, J. R. Yates, and A. J. Lotery, "Agerelated macular degeneration and the complement system," Immunobiology, vol. 217, no. 2, pp. 127-146, 2012.

[53] R. Medzhitov, "Origin and physiological roles of inflammation," Nature, vol. 454, no. 7203, pp. 428-435, 2008.

[54] D. Harman, "Aging: a theory based on free radical and radiation chemistry," Journal of gerontology, vol. 11, no. 3, pp. 298-300, 1956.

[55] J. M. Seddon, S. George, B. Rosner, and N. Rifai, "Progression of age-related macular degeneration: prospective assessment of C-reactive protein, interleukin 6, and other cardiovascular biomarkers," Archives of Ophthalmology, vol. 123, no. 6, pp. 774-782, 2005.

[56] Y. H. Wei, C. Y. Lu, H. C. Lee, C. Y. Pang, and Y. S. Ma, "Oxidative damage and mutation to mitochondrial DNA and age-dependent decline of mitochondrial respiratory function," Annals of the New York Academy of Sciences, vol. 854, pp. 155-170, 1998.

[57] S. Hekimi, J. Lapointe, and Y. Wen, "Taking a "good" look at free radicals in the aging process," Trends in Cell Biology, vol. 21, no. 10, pp. 569-576, 2011.

[58] A. Melo, L. Monteiro, R. M. Lima, D. M. Oliveira, M. D. Cerqueira, and R. S. El-Bachá, "Oxidative stress in neurodegenerative diseases: mechanisms and therapeutic perspectives," Oxidative Medicine and Cellular Longevity, vol. 2011, Article ID 467180, 14 pages, 2011.

[59] U. Garbin, A. F. Pasini, C. Stranieri et al., "Cigarette smoking blocks the protective expression of Nrf2/ARE pathway 
in peripheral mononuclear cells of young heavy smokers favouring inflammation," PLoS ONE, vol. 4, no. 12, Article ID e8225, 2009.

[60] P. C. Calder, N. Ahluwalia, F. Brouns et al., "Dietary factors and low-grade inflammation in relation to overweight and obesity," British Journal of Nutrition, vol. 106, no. 3, pp. 5-78, 2011.

[61] D. E. Heck, A. M. Vetrano, T. M. Mariano, and J. D. Laskin, "UVB light stimulates production of reactive oxygen species: unexpected role for catalase," The Journal of Biological Chemistry, vol. 278, no. 25, pp. 22432-22436, 2003.

[62] E. Naik and V. M. Dixit, "Mitochondrial reactive oxygen species drive proinflammatory cytokine production," Journal of Experimental Medicine, vol. 208, no. 3, pp. 417-420, 2011.

[63] G. J. Burton, "Oxygen, the Janus gas; its effects on human placental development and function," Journal of Anatomy, vol. 215, no. 1, pp. 27-35, 2009.

[64] H. Kajimoto, K. Hashimoto, S. N. Bonnet et al., "Oxygen activates the rho/rho-kinase pathway and induces RhoB and ROCK-1 expression in human and rabbit ductus arteriosus by increasing mitochondria-derived reactive oxygen species: a newly recognized mechanism for sustaining ductal constriction," Circulation, vol. 115, no. 13, pp. 1777-1788, 2007.

[65] J. Zhou, Y. P. Jang, S. R. Kim, and J. R. Sparrow, "Complement activation by photooxidation products of A2E, a lipofuscin constituent of the retinal pigment epithelium," Proceedings of the National Academy of Sciences of the United States of America, vol. 103, no. 44, pp. 16182-16187, 2006.

[66] J. Zhou, S. R. Kim, B. S. Westlund, and J. R. Sparrow, "Complement activation by bisretinoid constituents of RPE lipofuscin," Investigative Ophthalmology and Visual Science, vol. 50, no. 3, pp. 1392-1399, 2009.

[67] J. L. Dunaief, T. Dentchev, G. S. Ying, and A. H. Milam, "The role of apoptosis in age-related macular degeneration," Archives of Ophthalmology, vol. 120, no. 11, pp. 1435-1442, 2002.

[68] A. Takahashi, A. Masuda, M. Sun, V. E. Centonze, and B. Herman, "Oxidative stress-induced apoptosis is associated with alterations in mitochondrial caspase activity and Bcl2-dependent alterations in mitochondrial $\mathrm{pH}(\mathrm{pHm})$," Brain Research Bulletin, vol. 62, no. 6, pp. 497-504, 2004.

[69] M. Ushio-Fukai, "Redox signaling in angiogenesis: role of NADPH oxidase," Cardiovascular Research, vol. 71, no. 2, pp. 226-235, 2006.

[70] M. Ushio-Fukai, "VEGF signaling through NADPH oxidasederived ROS," Antioxidants and Redox Signaling, vol. 9, no. 6, pp. 731-739, 2007.

[71] C. Campa, C. Costagliola, C. Incorvaia et al., "Inflammatory mediators and angiogenic factors in choroidal neovascularization: pathogenetic interactions and therapeutic implications," Mediators of Inflammation, vol. 2010, Article ID 546826, 14 pages, 2010.

[72] H. Wang, E. S. Wittchen, and M. E. Hartnett, "Breaking barriers: insight into the pathogenesis of neovascular agerelated macular degeneration," Eye and Brain, vol. 3, pp. 19$28,2011$.

[73] D. H. Anderson, R. F. Mullins, G. S. Hageman, and L. V. Johnson, "A role for local inflammation in the formation of drusen in the aging eye," American Journal of Ophthalmology, vol. 134, no. 3, pp. 411-431, 2002.

[74] H. Gao and J. G. Hollyfield, "Aging of the human retina: differential loss of neurons and retinal pigment epithelial cells," Investigative Ophthalmology and Visual Science, vol. 33, no. 1, pp. 1-17, 1992.

[75] C. A. Curcio, C. L. Millican, K. A. Allen, and R. E. Kalina, "Aging of the human photoreceptor mosaic: evidence for selective vulnerability of rods in central retina," Investigative Ophthalmology and Visual Science, vol. 34, no. 12, pp. 32783296, 1993.

[76] D. A. Newsome, W. Huh, and W. R. Green, "Bruch's membrane age-related changes vary by region," Current Eye Research, vol. 6, no. 10, pp. 1211-1221, 1987.

[77] R. S. Ramrattan, T. L. Van der Schaft, C. M. Mooy, W. C. De Bruijn, P. G. H. Mulder, and P. T. V. M. De Jong, "Morphometric analysis of Bruch's membrane, the choriocapillaris, and the choroid in aging," Investigative Ophthalmology and Visual Science, vol. 35, no. 6, pp. 2857-2864, 1994.

[78] H. Xu, R. Dawson, J. V. Forrester, and J. Liversidge, "Identification of novel dendritic cell populations in normal mouse retina," Investigative Ophthalmology and Visual Science, vol. 48, no. 4, pp. 1701-1710, 2007.

[79] M. J. Walport, "Complement (first of two parts)," The New England Journal of Medicine, vol. 344, no. 14, pp. 1058-1066, 2001.

[80] M. J. Hogan, J. A. Alvarado, and J. E. Weddell, Histology of the Human Eye, WB Saunders Company, 1971.

[81] T. L. Van der Schaft, C. M. Mooy, W. C. De Bruijn, and P. T. V. M. de Jong, "Early stages of age-related macular degeneration: an immunofluorescence and electron microscopy study," British Journal of Ophthalmology, vol. 77, no. 10, pp. 657-661, 1993.

[82] R. F. Mullins and G. S. Hageman, "Histochemical comparison of ocular "drusen" in monkey and human," in Degenerative Retinal Diseases, M. M. La Vail, J. G. Hollyfield, and R. E. Anderson, Eds., pp. 1-10, Plenum, 1997.

[83] G. S. Hageman, R. F. Mullins, S. R. Russell, L. V. Johnson, and D. H. Anderson, "Vitronectin is a constituent of ocular drusen and the vitronectin gene is expressed in human retinal pigmented epithelial cells," The FASEB Journal, vol. 13, no. 3, pp. 477-484, 1999.

[84] G. S. Hageman and R. F. Mullins, "Molecular composition of drusen as related to substructural phenotype," Molecular vision, vol. 5, p. 28, 1999.

[85] L. V. Johnson, W. P. Leitner, M. K. Staples, and D. H. Anderson, "Complement activation and inflammatory processes in drusen formation and age related macular degeneration," Experimental Eye Research, vol. 73, no. 6, pp. 887-896, 2001.

[86] R. F. Mullins, N. Aptsiauri, and G. S. Hageman, "Structure and composition of drusen associated with glomerulonephritis: implications for the role of complement activation in drusen biogenesis," Eye, vol. 15, no. 3, pp. 390-395, 2001.

[87] L. V. Johnson, W. P. Leitner, A. J. Rivest, M. K. Staples, M. J. Radeke, and D. H. Anderson, "The Alzheimer's A $\beta$ peptide is deposited at sites of complement activation in pathologic deposits associated with aging and age-related macular degeneration," Proceedings of the National Academy of Sciences of the United States of America, vol. 99, no. 18, pp. 11830-11835, 2002.

[88] J. W. Crabb, M. Miyagi, X. Gu et al., "Drusen proteome analysis: an approach to the etiology of age-related macular degeneration," Proceedings of the National Academy of Sciences of the United States of America, vol. 99, no. 23, pp. 14682-14687, 2002. 
[89] H. Sakaguchi, M. Miyagi, K. G. Shadrach, M. E. Rayborn, J. W. Crabb, and J. G. Hollyfield, "Clusterin is present in drusen in age-related macular degeneration," Experimental Eye Research, vol. 74, no. 4, pp. 547-549, 2002.

[90] D. H. Anderson, K. C. Talaga, A. J. Rivest, E. Barron, G. S. Hageman, and L. V. Johnson, "Characterization of $\beta$ amyloid assemblies in drusen: the deposits associated with aging and age-related macular degeneration," Experimental Eye Research, vol. 78, no. 2, pp. 243-256, 2004.

[91] P. T. Johnson, K. E. Betts, M. J. Radeke, G. S. Hageman, D. H. Anderson, and L. V. Johnson, "Individuals homozygous for the age-related macular degeneration risk-conferring variant of complement factor $\mathrm{H}$ have elevated levels of CRP in the choroid," Proceedings of the National Academy of Sciences of the United States of America, vol. 103, no. 46, pp. 1745617461, 2006.

[92] M. Laine, H. Jarva, S. Seitsonen et al., "Y402H polymorphism of complement factor $\mathrm{H}$ affects binding affinity to C-reactive protein," Journal of Immunology, vol. 178, no. 6, pp. 38313836, 2007.

[93] J. Wang, K. Ohno-Matsui, T. Yoshida et al., "Altered function of factor I caused by amyloid $\beta$ : implication for pathogenesis of age-related macular degeneration from drusen," Journal of Immunology, vol. 181, no. 1, pp. 712-720, 2008.

[94] G. S. Hageman, P. J. Luthert, N. H. Victor Chong, L. V. Johnson, D. H. Anderson, and R. F. Mullins, "An integrated hypothesis that considers drusen as biomarkers of immunemediated processes at the RPE-Bruch's membrane interface in aging and age-related macular degeneration," Progress in Retinal and Eye Research, vol. 20, no. 6, pp. 705-732, 2001.

[95] A. O. Edwards, R. Ritter, K. J. Abel, A. Manning, C. Panhuysen, and L. A. Farrer, "Complement factor H polymorphism and age-related macular degeneration," Science, vol. 308, no. 5720, pp. 421-424, 2005.

[96] D. D. G. Despriet, C. C. W. Klaver, J. C. M. Witteman et al., "Complement factor $\mathrm{H}$ polymorphism, complement activators, and risk of age-related macular degeneration," Journal of the American Medical Association, vol. 296, no. 3, pp. 301-309, 2006.

[97] M. Li, P. Atmaca-Sonmez, M. Othman et al., "CFH haplotypes without the $\mathrm{Y} 402 \mathrm{H}$ coding variant show strong association with susceptibility to age-related macular degeneration," Nature Genetics, vol. 38, no. 9, pp. 1049-1054, 2006.

[98] P. J. Francis, D. W. Schultz, S. Hamon, J. Ott, R. G. Weleber, and M. L. Klein, "Haplotypes in the complement factor $\mathrm{H}$ $(\mathrm{CFH})$ gene: associations with drusen and advanced agerelated macular degeneration," PLoS ONE, vol. 2, no. 11, Article ID e1197, 2007.

[99] J. M. Seddon, P. J. Francis, S. George, D. W. Schultz, B. Rosner, and M. L. Klein, "Association of CFH Y402H and LOC387715 A69S with progression of age-related macular degeneration," Journal of the American Medical Association, vol. 297, no. 16, pp. 1793-1800, 2007.

[100] J. R. W. Yates, T. Sepp, B. K. Matharu et al., "Complement C3 variant and the risk of age-related macular degeneration," The New England Journal of Medicine, vol. 357, no. 6, pp. 553561, 2007.

[101] J. B. Maller, J. A. Fagerness, R. C. Reynolds, B. M. Neale, M. J. Daly, and J. M. Seddon, "Variation in complement factor 3 is associated with risk of age-related macular degeneration," Nature Genetics, vol. 39, no. 10, pp. 1200-1201, 2007.

[102] K. H. Park, B. L. Fridley, E. Ryu, N. Tosakulwong, and A. O. Edwards, "Complement component 3 (C3) haplotypes and risk of advanced age-related macular degeneration,"
Investigative Ophthalmology and Visual Science, vol. 50, no. 7, pp. 3386-3393, 2009.

[103] D. D. G. Despriet, C. M. van Duijn, B. A. Oostra et al., "Complement component $\mathrm{C} 3$ and risk of age-related macular degeneration," Ophthalmology, vol. 116, no. 3, pp. 474-480, 2009.

[104] J. A. Fagerness, J. B. Maller, B. M. Neale, R. C. Reynolds, M. J. Daly, and J. M. Seddon, "Variation near complement factor I is associated with risk of advanced AMD," European Journal of Human Genetics, vol. 17, no. 1, pp. 100-104, 2009.

[105] N. Kondo, H. Bessho, S. Honda, and A. Negi, "Additional evidence to support the role of a common variant near the complement factor i gene in susceptibility to age-related macular degeneration," European Journal of Human Genetics, vol. 18, no. 6, pp. 634-635, 2010.

[106] B. Gold, J. E. Merriam, J. Zernant et al., "Variation in factor B (BF) and complement component $2(\mathrm{C} 2)$ genes is associated with age-related macular degeneration," Nature Genetics, vol. 38 , no. 4, pp. 458-462, 2006.

[107] J. Jakobsdottir, Y. P. Conley, D. E. Weeks, R. E. Ferrell, and M. B. Gorin, "C2 and CFB genes in age-related maculopathy and joint action with CFH and LOC387715 genes," PLOS ONE, vol. 3, no. 5, Article ID e2199, 2008.

[108] G. S. Hageman, L. S. Hancox, A. J. Taiber et al., "Extended haplotypes in the complement factor $\mathrm{H}(\mathrm{CFH})$ and $\mathrm{CFH}-$ related (CFHR) family of genes protect against age-related macular degeneration: characterization, ethnic distribution and evolutionary implications," Annals of Medicine, vol. 38, no. 8, pp. 592-604, 2006.

[109] A. E. Hughes, N. Orr, H. Esfandiary, M. Diaz-Torres, T. Goodship, and U. Chakravarthy, "A common CFH haplotype, with deletion of CFHR1 and CFHR3, is associated with lower risk of age-related macular degeneration," Nature Genetics, vol. 38, no. 10, pp. 1173-1177, 2006.

[110] H. Zhang, M. A. Morrison, A. DeWan et al., "The NEI/NCBI dbGAP database: genotypes and haplotypes that may specifically predispose to risk of neovascular age-related macular degeneration," BMC Medical Genetics, vol. 9, p. 51, 2008.

[111] P. J. Francis and M. L. Klein, "Update on the role of genetics in the onset of age-related macular degeneration," Journal of Clinical Ophthalmology, vol. 5, pp. 1127-1133, 2011.

[112] J. M. Seddon, R. Reynolds, J. Maller, J. A. Fagerness, M. J. Daly, and B. Rosner, "Prediction model for prevalence and incidence of advanced age-related macular degeneration based on genetic, demographic, and environmental variables," Investigative Ophthalmology and Visual Science, vol. 50, no. 5, pp. 2044-2053, 2009.

[113] T. W. Du Clos, "Function of C-reactive protein," Annals of Medicine, vol. 32, no. 4, pp. 274-278, 2000.

[114] F. Parmeggiani, D. Gemmati, C. Costagliola et al., "Genetic predictors of response to photodynamic therapy," Molecular Diagnosis \& Therapy, vol. 15, no. 4, pp. 195-210, 2011.

[115] S. Hakobyan, C. L. Harris, C. W. Van Den Berg et al., "Complement factor $\mathrm{H}$ binds to denatured rather than to native pentameric C-reactive protein," The Journal of Biological Chemistry, vol. 283, no. 45, pp. 30451-30460, 2008.

[116] A. P. Herbert, J. A. Deakin, C. Q. Schmidt et al., "Structure shows that a glycosaminoglycan and protein recognition site in factor $\mathrm{H}$ is perturbed by age-related macular degeneration-linked single nucleotide polymorphism," The Journal of Biological Chemistry, vol. 282, no. 26, pp. 18960 18968, 2007. 
[117] J. Yu, P. Wiita, R. Kawaguchi et al., "Biochemical analysis of a common human polymorphism associated with agerelated macular degeneration," Biochemistry, vol. 46, no. 28, pp. 8451-8461, 2007.

[118] S. J. Perkins, R. Nan, A. I. Okemefuna, K. Li, S. Khan, and A. Miller, "Multiple interactions of complement factor $\mathrm{h}$ with its ligands in solution: a progress report," Advances in Experimental Medicine and Biology, vol. 703, pp. 25-47, 2010.

[119] T. Hong, A. G. Tan, P. Mitchell, and J. J. Wang, "A review and meta-analysis of the association between C-reactive protein and age-related macular degeneration," Survey of Ophthalmology, vol. 56, no. 3, pp. 184-194, 2011.

[120] L. Robman, P. N. Baird, P. N. Dimitrov, A. J. Richardson, and R. H. Guymer, "C-reactive protein levels and complement factor $\mathrm{H}$ polymorphism interaction in age-related macular degeneration and its progression," Ophthalmology, vol. 117, no. 10, pp. 1982-1988, 2010.

[121] D. A. Schaumberg, W. G. Christen, P. Kozlowski, D. T. Miller, P. M. Ridker, and R. Y. L. Zee, "A prospective assessment of the $\mathrm{Y} 402 \mathrm{H}$ variant in complement factor $\mathrm{H}$, genetic variants in C-reactive protein, and risk of agerelated macular degeneration," Investigative Ophthalmology and Visual Science, vol. 47, no. 6, pp. 2336-2340, 2006.

[122] I. K. Kim, F. Ji, M. A. Morrison et al., "Comprehensive analysis of CRP, CFH Y402H and environmental risk factors on risk of neovascular age-related macular degeneration," Molecular Vision, vol. 14, pp. 1487-1495, 2008.

[123] S. K. Iyengar, D. Song, B. E. K. Klein et al., "Dissection of genomewide-scan data in extended families reveals a major locus and oligogenic susceptibility for age-related macular degeneration," American Journal of Human Genetics, vol. 74, no. 1, pp. 20-39, 2004.

[124] J. Majewski, D. W. Schultz, R. G. Weleber et al., "Age-related macular degeneration - a genome scan in extended families," American Journal of Human Genetics, vol. 73, no. 3, pp. 540550, 2003.

[125] J. M. Seddon, S. L. Santangelo, K. Book, S. Chong, and J. Cote, "A genomewide scan for age-related macular degeneration provides evidence for linkage to several chromosomal regions," American Journal of Human Genetics, vol. 73, no. 4, pp. 780-790, 2003.

[126] D. E. Weeks, Y. P. Conley, T. S. Mah et al., "A full genome scan for age-related maculopathy," Human Molecular Genetics, vol. 9, no. 9, pp. 1329-1349, 2000.

[127] J. Jakobsdottir, Y. P. Conley, D. E. Weeks, T. S. Mah, R. E. Ferrell, and M. B. Gorin, "Susceptibility genes for age-related maculopathy on chromosome 10q26," American Journal of Human Genetics, vol. 77, no. 3, pp. 389-407, 2005.

[128] A. Rivera, S. A. Fisher, L. G. Fritsche et al., "Hypothetical LOC387715 is a second major susceptibility gene for agerelated macular degeneration, contributing independently of complement factor $\mathrm{H}$ to disease risk," Human Molecular Genetics, vol. 14, no. 21, pp. 3227-3236, 2005.

[129] A. DeWan, M. Liu, S. Hartman et al., "HTRA1 promoter polymorphism in wet age-related macular degeneration," Science, vol. 314, no. 5801, pp. 989-992, 2006.

[130] Z. Yang, N. J. Camp, H. Sun et al., "A variant of the HTRA1 gene increases susceptibility to age-related macular degeneration," Science, vol. 314, no. 5801, pp. 992-993, 2006.

[131] A. Kanda, W. Chen, M. Othman et al., "A variant of mitochondrial protein LOC387715/ARMS2, not HTRA1, is strongly associated with age-related macular degeneration," Proceedings of the National Academy of Sciences of the United States of America, vol. 104, no. 41, pp. 16227-16232, 2007.
[132] G. Wang, K. L. Spencer, B. L. Court et al., "Localization of age-related macular degeneration-associated ARMS2 in cytosol, not mitochondria," Investigative Ophthalmology and Visual Science, vol. 50, no. 7, pp. 3084-3090, 2009.

[133] E. Kortvely, S. M. Hauck, G. Duetsch et al., "ARMS2 is a constituent of the extracellular matrix providing a link between familial and sporadic age-related macular degenerations," Investigative Ophthalmology and Visual Science, vol. 51, no. 1, pp. 79-88, 2010.

[134] U. Friedrich, C. A. Myers, L. G. Fritsche et al., "Risk-and nonrisk-associated variants at the 10q26 AMD locus influence ARMS2 mRNA expression but exclude pathogenic effects due to protein deficiency," Human Molecular Genetics, vol. 20, no. 7, Article ID ddr020, pp. 1387-1399, 2011.

[135] E. An, S. Sen, S. K. Park, H. Gordish-Dressman, and Y. Hathout, "Identification of novel substrates for the serine protease HTRA1 in the human RPE secretome," Investigative Ophthalmology and Visual Science, vol. 51, no. 7, pp. 33793386, 2010.

[136] A. Kanda, D. Stambolian, W. Chen, C. A. Curcio, G. R. Abecasis, and A. Swaroop, "Age-related macular degeneration-associated variants at chromosome 10q26 do not significantly alter ARMS2 and HTRA1 transcript levels in the human retina," Molecular Vision, vol. 16, pp. 1317-1323, 2010.

[137] Z. Yang, Z. Tong, Y. Chen et al., "Genetic and functional dissection of HTRA1 and LOC387715 in age-related macular degeneration," PLoS Genetics, vol. 6, no. 2, Article ID e1000836, 2010.

[138] T. K. Ng, G. H. Yam, W. Q. Chen et al., "Interactive expressions of HtrA1 and VEGF in human vitreous humors and fetal RPE cells," Investigative Ophthalmology \& Visual Science, vol. 52, no. 6, pp. 3706-3712, 2011.

[139] S. Schmidt, M. A. Hauser, W. K. Scott et al., "Cigarette smoking strongly modifies the association of LOC387715 and age-related macular degeneration," American Journal of Human Genetics, vol. 78, no. 5, pp. 852-864, 2006.

[140] Y. P. Conley, J. Jakobsdottir, T. Mah et al., "CFH, ELOVL4, PLEKHA1 and LOC387715 genes and susceptibility to agerelated maculopathy: AREDS and CHS cohorts and metaanalyses," Human Molecular Genetics, vol. 15, no. 21, pp. 3206-3218, 2006.

[141] Y. Y. Tsai, J. M. Lin, L. Wan et al., "Interleukin gene polymorphisms in age-related macular degeneration," Investigative Ophthalmology and Visual Science, vol. 49, no. 2, pp. 693-698, 2008.

[142] S. Zareparsi, M. Buraczynska, K. E. H. Branham et al., "Tolllike receptor 4 variant D299G is associated with susceptibility to age-related macular degeneration," Human Molecular Genetics, vol. 14, no. 11, pp. 1449-1455, 2005.

[143] Z. Yang, C. Stratton, P. J. Francis et al., "Toll-like receptor 3 and geographic atrophy in age-related macular degeneration," The New England Journal of Medicine, vol. 359, no. 14, pp. 1456-1463, 2008.

[144] C. C. W. Klaver, M. Kliffen, C. M. Van Duijn et al., "Genetic association of apolipoprotein $\mathrm{E}$ with age-related macular degeneration," American Journal of Human Genetics, vol. 63, no. 1, pp. 200-206, 1998.

[145] P. N. Baird, E. Guida, D. T. Chu, H. T. V. Vu, and R. H. Guymer, "The $\varepsilon 2$ and $\varepsilon 4$ alleles of the apolipoprotein gene are associated with age-related macular degeneration," Investigative Ophthalmology and Visual Science, vol. 45, no. 5, pp. 1311-1315, 2004. 
[146] P. N. Baird, A. J. Richardson, L. D. Robman et al., "Apolipoprotein (APOE) gene is associated with progression of age-related macular degeneration (AMD)," Human Mutation, vol. 27, no. 4, pp. 337-342, 2006.

[147] R. Allikmets, N. F. Shroyer, N. Singh et al., "Mutation of the Stargardt disease gene (ABCR) in age-related macular degeneration," Science, vol. 277, no. 5333, pp. 1805-1807, 1997.

[148] R. Allikmets, "Further evidence for an association of ABCR alleles with age-related macular degeneration. The International ABCR Screening Consortium," The American Journal of Human Genetics, vol. 67, no. 2, pp. 487-491, 2000.

[149] C. Combadière, C. Feumi, W. Raoul et al., "CX3CR1dependent subretinal microglia cell accumulation is associated with cardinal features of age-related macular degeneration," Journal of Clinical Investigation, vol. 117, no. 10, pp. 2920-2928, 2007.

[150] J. M. Seddon, R. Reynolds, and B. Rosner, "Associations of smoking, body mass index, dietary lutein, and the LIPC genetic variant rs10468017 with advanced age-related macular degeneration," Molecular Vision, vol. 16, pp. 24122424, 2010.

[151] B. M. Neale, J. Fagerness, R. Reynolds et al., "Genomewide association study of advanced age-related macular degeneration identifies a role of the hepatic lipase gene (LIPC)," Proceedings of the National Academy of Sciences of the United States of America, vol. 107, no. 16, pp. 7395-7400, 2010.

[152] W. Chen, D. Stambolian, A. O. Edwards et al., "Genetic variants near TIMP3 and high-density lipoprotein-associated loci influence susceptibility to age-related macular degeneration," Proceedings of the National Academy of Sciences of the United States of America, vol. 107, no. 16, pp. 7401-7406, 2010.

[153] P. N. Baird, D. Chu, E. Guida, H. T. V. Vu, and R. Guymer, "Association of the M55L and Q192R paraoxonase gene polymorphisms with age-related macular degeneration," American Journal of Ophthalmology, vol. 138, no. 4, pp. 665666, 2004.

[154] J. Tuo, B. Ning, C. M. Bojanowski et al., "Synergic effect of polymorphisms in ERCC6 5' flanking region and complement factor $\mathrm{H}$ on age-related macular degeneration predisposition," Proceedings of the National Academy of Sciences of the United States of America, vol. 103, no. 24, pp. 9256-9261, 2006.

[155] Y. P. Conley, A. Thalamuthu, J. Jakobsdottir et al., "Candidate gene analysis suggests a role for fatty acid biosynthesis and regulation of the complement system in the etiology of agerelated maculopathy," Human Molecular Genetics, vol. 14, no. 14, pp. 1991-2002, 2005.

[156] E. M. Stone, T. A. Braun, S. R. Russell et al., "Missense variations in the fibulin 5 gene and age-related macular degeneration," The New England Journal of Medicine, vol. 351, no. 4, pp. 346-353, 2004.

[157] D. W. Schultz, M. L. Klein, A. J. Humpert et al., "Analysis of the ARMD1 locus: evidence that a mutation in HEMICENTIN-1 is associated with age-related macular degeneration in a large family," Human Molecular Genetics, vol. 12, no. 24, pp. 3315-3323, 2003.

[158] S. Ennis, C. Jomary, R. Mullins et al., "Association between the SERPING1 gene and age-related macular degeneration: a two-stage case-control study," The Lancet, vol. 372, no. 9652, pp. 1828-1834, 2008.
[159] I. Nakata, K. Yamashiro, R. Yamada et al., "Association between the serping1 gene and age-related macular degeneration and polypoidal choroidal vasculopathy in japanese," PLoS ONE, vol. 6, no. 4, Article ID e19108, 2011.

[160] J. L. Haines, N. Schnetz-Boutaud, S. Schmidt et al., "Functional candidate genes in age-related macular degeneration: significant association with VEGF, VLDLR, and LRP6," Investigative Ophthalmology and Visual Science, vol. 47, no. 1, pp. 329-335, 2006.

[161] A. J. Churchill, J. G. Carter, H. C. Lovell et al., "VEGF polymorphisms are associated with neovascular age-related macular degeneration," Human Molecular Genetics, vol. 15, no. 19, pp. 2955-2961, 2006.

[162] A. Galan, A. Ferlin, L. Caretti et al., "Association of agerelated macular degeneration with polymorphisms in vascular endothelial growth factor and its receptor," Ophthalmology, vol. 117, no. 9, pp. 1769-1774, 2010.

[163] Y. Wang, V. M. Wang, and C. C. Chan, "The role of antiinflammatory agents in age-related macular degeneration (AMD) treatment," Eye, vol. 25, no. 2, pp. 127-139, 2011.

[164] Age-Related Eye Disease Study Research Group, “The AgeRelated Eye Disease Study (AREDS): design implications. AREDS report no. 1," Control Clinical Trials, vol. 20, no. 6, pp. 573-600, 1999.

[165] N. Krishnadev, A. D. Meleth, and E. Y. Chew, "Nutritional supplements for age-related macular degeneration," Current Opinion in Ophthalmology, vol. 21, no. 3, pp. 184-189, 2010.

[166] J. H. Olson, J. C. Erie, and S. J. Bakri, "Nutritional supplementation and age-related macular degeneration," Seminars in Ophthalmology, vol. 26, no. 3, pp. 131-136, 2011.

[167] J. T. Wilkinson and F. W. Fraunfelder, "Use of herbal medicines and nutritional supplements in ocular disorders: an evidence-based review," Drugs, vol. 71, no. 18, pp. 24212434, 2011.

[168] H. P. Sin, D. T. Liu, and D. S. Lam, "Lifestyle modification, nutritional and vitaminssupplements for age-related macular degeneration," Acta Ophthalmologica. In press.

[169] S. Zeng, J. Hernández, and R. F. Mullins, "Effects of antioxidant components of AREDS vitamins and zinc ions on endothelial cell activation: implications for macular degeneration," Investigative Ophthalmology \& Visual Science, vol. 53, no. 2, pp. 1041-1047, 2012.

[170] G. Weigert, S. Kaya, B. Pemp et al., "Effects of lutein supplementation on macular pigment optical density and visual acuity in patients with age-related macular degeneration," Investigative Ophthalmology \& Visual Science, vol. 52, no. 11, pp. 8174-8178, 2011.

[171] A. Kijlstra, Y. Tian, E. R. Kelly, and T. T. Berendschot, "Lutein: more than just a filter for blue light," Progress in Retinal and Eye Research, vol. 31, no. 4, pp. 303-315, 2012.

[172] P. L. Penfold, J. G. Wong, J. Gyory, and F. A. Billson, "Effects of triamcinolone acetonide on microglial morphology and quantitative expression of MHC-II in exudative age-related macular degeneration," Clinical and Experimental Ophthalmology, vol. 29, no. 3, pp. 188-192, 2001.

[173] E. M. Becerra, F. Morescalchi, F. Gandolfo et al., "Clinical evidence of intravitreal triamcinolone acetonide in the management of age-related macular degeneration," Current drug targets, vol. 12, no. 2, pp. 149-172, 2011.

[174] R. B. Nussenblatt, G. Byrnes, H. N. Sen et al., "A randomized pilot study of systemic immunosuppression in the treatment of age-related macular degeneration with choroidal neovascularization," Retina, vol. 30, no. 10, pp. 1579-1587, 2010. 
[175] L. Arias, J. M. Caminal, M. B. Badia, M. J. Rubio, J. Catala, and O. Pujol, "Intravitreal infliximab in patients with macular degeneration who are nonresponders to antivascular endothelial growth factor therapy," Retina, vol. 30, no. 10, pp. 1601-1608, 2010.

[176] U. Chakravarthy, G. Soubrane, F. Bandello et al., "Evolving European guidance on the medical management of neovascular age related macular degeneration," British Journal of Ophthalmology, vol. 90, no. 9, pp. 1188-1196, 2006.

[177] R. Wormald, J. Evans, L. Smeeth, and K. Henshaw, "Photodynamic therapy for neovascular age-related macular degeneration," Cochrane Database of Systematic Reviews, no. 3, p. CD002030, 2007.

[178] S. S. Vedula and M. G. Krzystolik, "Antiangiogenic therapy with anti-vascular endothelial growth factor modalities for neovascular age-related macular degeneration," Cochrane Database of Systematic Reviews, no. 2, p. CD005139, 2008.

[179] J. L. Colquitt, J. Jones, S. C. Tan, A. Takeda, A. J. Clegg, and A. Price, "Ranibizumab and pegaptanib for the treatment of age-related macular degeneration: a systematic review and economic evaluation," Health Technology Assessment, vol. 12, no. 16, 2008.

[180] P. Mitchell, J. F. Korobelnik, P. Lanzetta et al., "Ranibizumab (Lucentis) in neovascular age-related macular degeneration: evidence from clinical trials," British Journal of Ophthalmology, vol. 94, no. 1, pp. 2-13, 2010.

[181] D. F. Martin, M. G. Maguire, G. S. Ying, J. E. Grunwald, S. L. Fine, and G. J. Jaffe, "Ranibizumab and bevacizumab for neovascular age-related macular degeneration," The New England Journal of Medicine, vol. 364, no. 20, pp. 1897-1908, 2011.

[182] P. J. Rosenfeld, "Bevacizumab versus ranibizumab for AMD," The New England Journal of Medicine, vol. 364, no. 20, pp. 1966-1967, 2011.

[183] F. Ziemssen and B. Sobolewska, "Therapeutic efficacy of bevacizumab for age-related macular degeneration: what are the implications of CATT for routine management?" Drugs \& Aging, vol. 28, no. 11, pp. 853-865, 2011.

[184] J. Davis, T. W. Olsen, M. Stewart, and P. Sternberg Jr., "How the comparison of age-related macular degeneration treatments trial results will impact clinical care," American Journal of Ophthalmology, vol. 152, no. 4, pp. 509-514, 2011.

[185] K. G. Csaky, "Comparison of age-related macular degeneration treatment trials: what did we learn?" Retina, vol. 32, no. 3, pp. 413-416, 2012.

[186] D. F. Martin, M. G. Maguire, S. L. Fine et al., "Ranibizumab and bevacizumab for treatment of neovascular age-related macular degeneration: two-year results," Ophthalmology, vol. 119, no. 7, pp. 1388-1398, 2012.

[187] Clinical Trials.gov identifier: NCT00766649, "Sirolimus to treat geographic atrophy associated with age-related macular degeneration", 2010, http://www.clinicaltrial.gov/ct2/show/ NCT00766649.

[188] M. Patel and C. C. Chan, "Immunopathological aspects of age-related macular degeneration," Seminars in Immunopathology, vol. 30, no. 2, pp. 97-110, 2008.

[189] A. J. Augustin, S. Puls, and I. Offermann, "Triple therapy for choroidal neovascularization due to age-related macular degeneration: verteporfin PDT, bevacizumab, and dexamethasone," Retina, vol. 27, no. 2, pp. 133-140, 2007.

[190] S. J. Bakri, S. M. Couch, C. A. McCannel, and A. O. Edwards, "Same-day triple therapy with photodynamic therapy, intravitreal dexamethasone, and bevacizumab in wet age-related macular degeneration," Retina, vol. 29, no. 5, pp. 573-578, 2009.

[191] D. Ehmann and R. García, "Triple therapy for neovascular age-related macular degeneration (verteporfin photodynamic therapy, intravitreal dexamethasone, and intravitreal bevacizumab)," Canadian Journal of Ophthalmology, vol. 45, no. 1, pp. 36-40, 2010.

[192] R. Forte, P. Bonavolontà, Y. Benayoun, J. P. Adenis, and P. Y. Robert, "Intravitreal ranibizumab and bevacizumab in combination with full-fluence verteporfin therapy and dexamethasone for exudative age-related macular degeneration," Ophthalmic Research, vol. 45, no. 3, pp. 129-134, 2011.

[193] S. Sivaprasad, S. Patra, J. Dacosta et al., "A pilot study on the combination treatment of reduced-fluence photodynamic therapy, intravitreal ranibizumab, intravitreal dexamethasone and oral minocycline for neovascular agerelated macular degeneration," Ophthalmologica, vol. 225, no. 4, pp. 200-206, 2011.

[194] M. Singer, S. S. Patel, S. U. Harvey, C. C. Liu, X. Y. Li, and S. M. Whitcup, "Dexamethasone intravitreal implant (DEX implant) alone and as an adjunct to ranibizumab for the treatment of choroidal neovascularization $(\mathrm{CNV})$ secondary to age-related macular degeneration (AMD)," in Proceedings of the Association for Research in Vision and Ophthalmology, Poster Presentation 3536/A334, 2011.

[195] U. Schmidt-Erfurth, S. Michels, I. Barbazetto, and H. Laqua, "Photodynamic effects on choroidal neovascularization and physiological choroid," Investigative Ophthalmology and Visual Science, vol. 43, no. 3, pp. 830-841, 2002.

[196] S. Michels and U. Schmidt-Erfurth, "Sequence of early vascular events after photodynamic therapy," Investigative Ophthalmology and Visual Science, vol. 44, no. 5, pp. 21472154, 2003.

[197] U. Schmidt-Erfurth, M. Niemeyer, W. Geitzenauer, and S. Michels, "Time course and morphology of vascular effects associated with photodynamic therapy," Ophthalmology, vol. 112, no. 12, pp. 2061-2069, 2005.

[198] M. A. Brantley Jr., A. M. Fang, J. M. King, A. Tewari, S. M. Kymes, and A. Shiels, "Association of complement factor $\mathrm{H}$ and LOC387715 genotypes with response of exudative agerelated macular degeneration to intravitreal bevacizumab," Ophthalmology, vol. 114, no. 12, pp. 2168-2173, 2007.

[199] S. P. Seitsonen, I. E. Järvelä, S. Meri, P. V. Tommila, P. H. Ranta, and I. J. Immonen, "The effect of complement factor $\mathrm{H} \mathrm{Y} 402 \mathrm{H}$ polymorphism on the outcome of photodynamic therapy in age-related macular degeneration," European Journal of Ophthalmology, vol. 17, no. 6, pp. 943-949, 2007.

[200] F. Parmeggiani, C. Costagliola, D. Gemmati et al., "Predictive role of coagulation-balance gene polymorphisms in the efficacy of photodynamic therapy with verteporfin for classic choroidal neovascularization secondary to age-related macular degeneration," Pharmacogenetics and Genomics, vol. 17, no. 12, pp. 1039-1046, 2007.

[201] T. M. Ranchod, J. R. Guercio, G. S. Ying, A. J. Brucker, and R. A. Stoltz, "Effect of aspirin therapy on photodynamic therapy with verteporfin for choroidal neovascularization," Retina, vol. 28, no. 5, pp. 711-716, 2008.

[202] F. Parmeggiani, C. Costagliola, D. Gemmati et al., "Coagulation gene predictors of photodynamic therapy for occult choroidal neovascularization in age-related macular degeneration," Investigative Ophthalmology and Visual Science, vol. 49, no. 7, pp. 3100-3106, 2008. 
[203] S. V. Goverdhan, S. Hannan, R. B. Newsom, A. J. Luff, H. Griffiths, and A. J. Lotery, "An analysis of the CFH Y402H genotype in AMD patients and controls from the UK, and response to PDT treatment," Eye, vol. 22, no. 6, pp. 849-854, 2008.

[204] I. Chowers, T. Meir, M. Lederman et al., "Sequence variants in HTRA1 and LOC387715/ARMS2 and phenotype and response to photodynamic therapy in neovascular agerelated macular degeneration in populations from Israel," Molecular Vision, vol. 14, pp. 2263-2271, 2008.

[205] A. Y. Lee, A. K. Raya, S. M. Kymes, A. Shiels, and M. A. Brantley Jr., "Pharmacogenetics of complement factor $\mathrm{H}(\mathrm{Y} 402 \mathrm{H})$ and treatment of exudative age-related macular degeneration with ranibizumab," British Journal of Ophthalmology, vol. 93, no. 5, pp. 610-613, 2009.

[206] M. A. Brantley Jr., S. L. Edelstein, J. M. King et al., "Association of complement factor $\mathrm{H}$ and LOC387715 genotypes with response of exudative age-related macular degeneration to photodynamic therapy," Eye, vol. 23, no. 3, pp. 626-631, 2009.

[207] X. Feng, J. Xiao, B. Longville et al., "Complement factor H $\mathrm{Y} 402 \mathrm{H}$ and C-reactive protein polymorphism and photodynamic therapy response in age-related macular degeneration," Ophthalmology, vol. 116, no. 10, pp. 1908-e1, 2009.

[208] F. Parmeggiani, D. Gemmati, C. Costagliola, A. Sebastiani, and C. Incorvaia, "Predictive role of C677T MTHFR polymorphism in variable efficacy of photodynamic therapy for neovascular age-related macular degeneration," Pharmacogenomics, vol. 10, no. 1, pp. 81-95, 2009.

[209] F. Parmeggiani, D. Gemmati, C. Costagliola, A. Sebastiani, and C. Incorvaia, "Predictive role of gene polymorphisms affecting thrombin-generation pathway in variable efficacy of photodynamic therapy for neovascular age-related macular degeneration," Recent Patents on DNA and Gene Sequences, vol. 3, no. 2, pp. 114-122, 2009.

[210] S. J. Teper, A. Nowinska, J. Pilat, A. Palucha, and E. Wylegala, "Involvement of genetic factors in the response to a variable-dosing ranibizumab treatment regimen for agerelated macular degeneration," Molecular Vision, vol. 16, pp. 2598-2604, 2010.

[211] D. Imai, K. Mori, K. Horie-Inoue et al., "CFH, VEGF, and PEDF genotypes and the response to intravitreous injection of bevacizumab for the treatment of age-related macular degeneration," Journal of Ocular Biology, Diseases, and Informatics, vol. 3, no. 2, pp. 53-59, 2010.

[212] I. Immonen, S. Seitsonen, P. Tommila et al., "Vascular endothelial growth factor gene variation and the response to photodynamic therapy in age-related macular degeneration," Ophthalmology, vol. 117, no. 1, pp. 103-108, 2010.

[213] B. S. Shastry, "Genetic diversity and medicinal drug response in eye care," Graefe's Archive for Clinical and Experimental Ophthalmology, vol. 248, no. 8, pp. 1057-1061, 2010.

[214] B. Kloeckener-Gruissem, D. Barthelmes, S. Labs et al., "Genetic association with response to intravitreal ranibizumab in patients with neovascular AMD," Investigative Ophthalmology \& Visual Science, vol. 52, no. 7, pp. 46944702, 2011.

[215] C. Nischler, H. Oberkofler, C. Ortner et al., "Complement factor $\mathrm{H} \mathrm{Y} 402 \mathrm{H}$ gene polymorphism and response to intravitreal bevacizumab in exudative age-related macular degeneration," Acta Ophthalmologica, vol. 89, no. 4, pp. e344e349, 2011.
[216] F. Parmeggiani, C. Costagliola, C. Incorvaia, A. Sebastiani, and D. Gemmati, "Pharmacogenetic aspects in therapeutic management of subfoveal choroidal neovascularisation: role of factor XIII-A 185 T-allele," Current drug targets, vol. 12, no. 2, pp. 138-148, 2011.

[217] T. Tsuchihashi, K. Mori, K. Horie-Inoue et al., "Complement factor $\mathrm{H}$ and high-temperature requirement A-1 genotypes and treatment response of age-related macular degeneration," Ophthalmology, vol. 118, no. 1, pp. 93-100, 2011.

[218] K. Ramo, S. M. Cashman, and R. Kumar-Singh, "Evaluation of adenovirus-delivered human CD59 as a potential therapy for AMD in a model of human membrane attack complex formation on murine RPE," Investigative Ophthalmology and Visual Science, vol. 49, no. 9, pp. 4126-4136, 2008.

[219] J. Gandhi, S. M. Cashman, and R. Kumar-Singh, "Soluble CD59 expressed from an adenovirus in vivo is a potent inhibitor of complement deposition on murine liver vascular endothelium," PLoS ONE, vol. 6, no. 6, Article ID e21621, 2011.

[220] J. H. Sweigard, S. M. Cashman, and R. Kumar-Singh, "Adenovirus-mediated delivery of CD46 attenuates the alternative complement pathway on RPE: implications for agerelated macular degeneration," Gene Therapy, vol. 18, no. 6, pp. 613-621, 2011.

[221] N. Kuno and S. Fujii, "Biodegradable intraocular therapies for retinal disorders: progress to date," Drugs and Aging, vol. 27, no. 2, pp. 117-134, 2010.

[222] N. J. S. London, A. Chiang, and J. A. Haller, "The dexamethasone drug delivery system: indications and evidence," Advances in Therapy, vol. 28, no. 5, pp. 351-366, 2011.

[223] J. R. de Oliveira Dias, E. B. Rodrigues, M. Maia, O. Magalhães, F. M. Penha, and M. E. Farah, "Cytokines in neovascular age-related macular degeneration: fundamentals of targeted combination therapy," British Journal of Ophthalmology, vol. 95, no. 12, pp. 1631-1637, 2011.

[224] B. D. Packard and J. M. Weiler, "Steroids inhibit activation of the alternative-amplification pathway of complement," Infection and Immunity, vol. 40, no. 3, pp. 1011-1014, 1983.

[225] P. J. Barnes, "Anti-inflammatory actions of glucocorticoids: molecular mechanisms," Clinical Science, vol. 94, no. 6, pp. 557-572, 1998. 


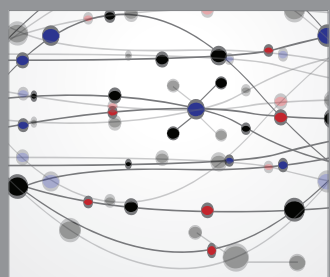

The Scientific World Journal
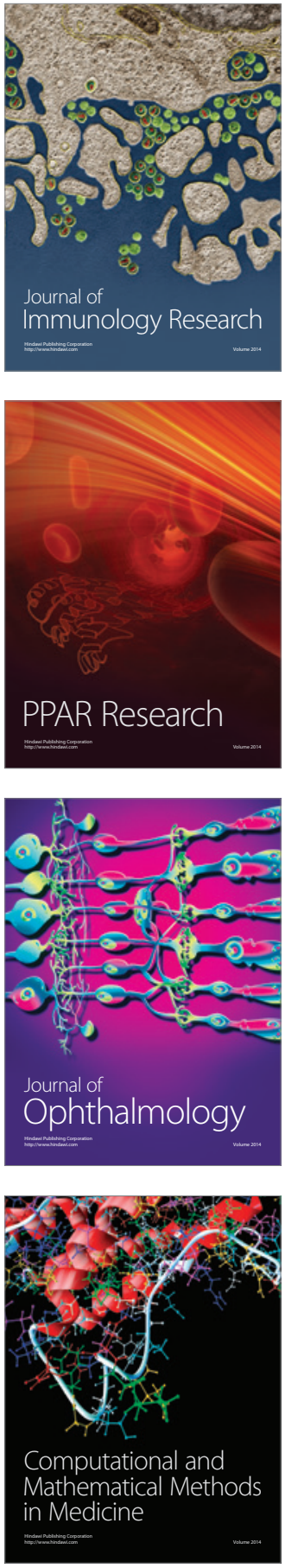

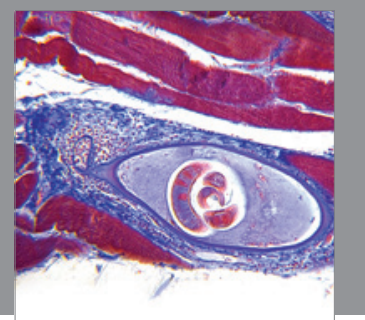

Gastroenterology

Research and Practice
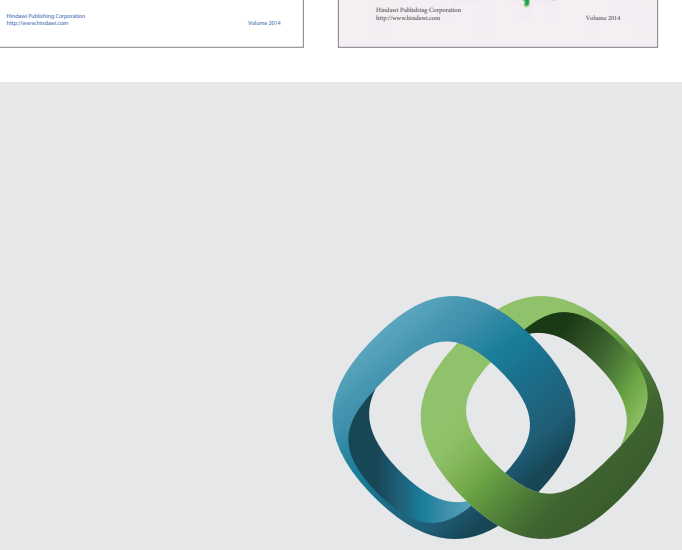

\section{Hindawi}

Submit your manuscripts at

http://www.hindawi.com
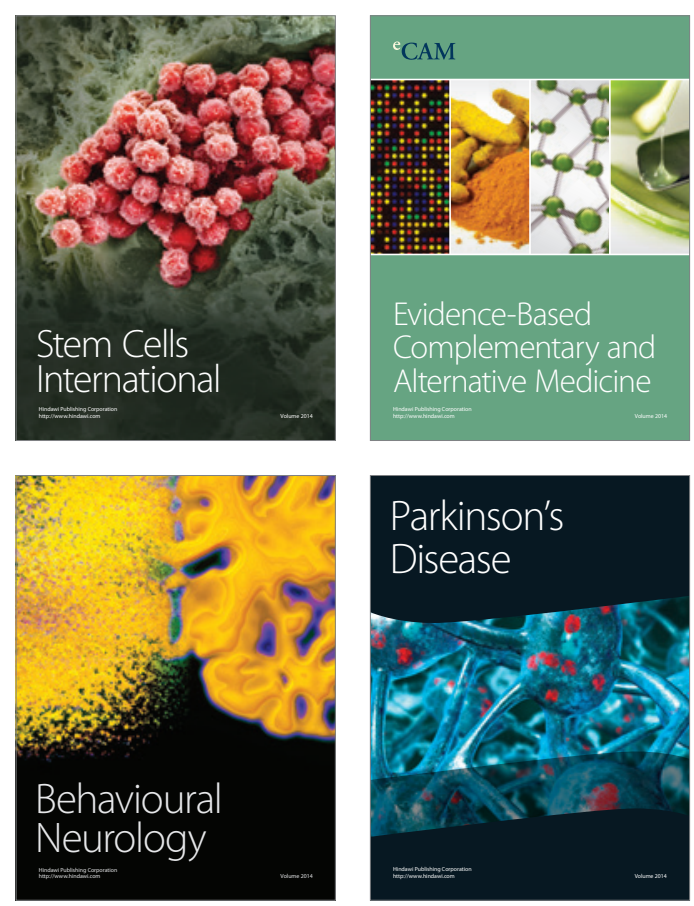

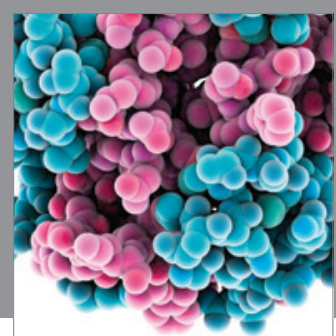

Journal of
Diabetes Research

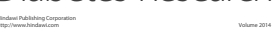

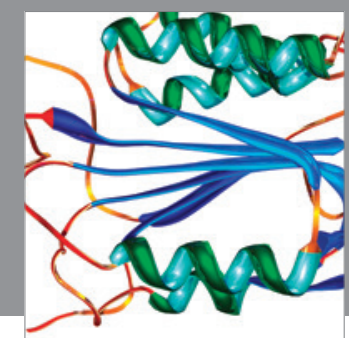

Disease Markers
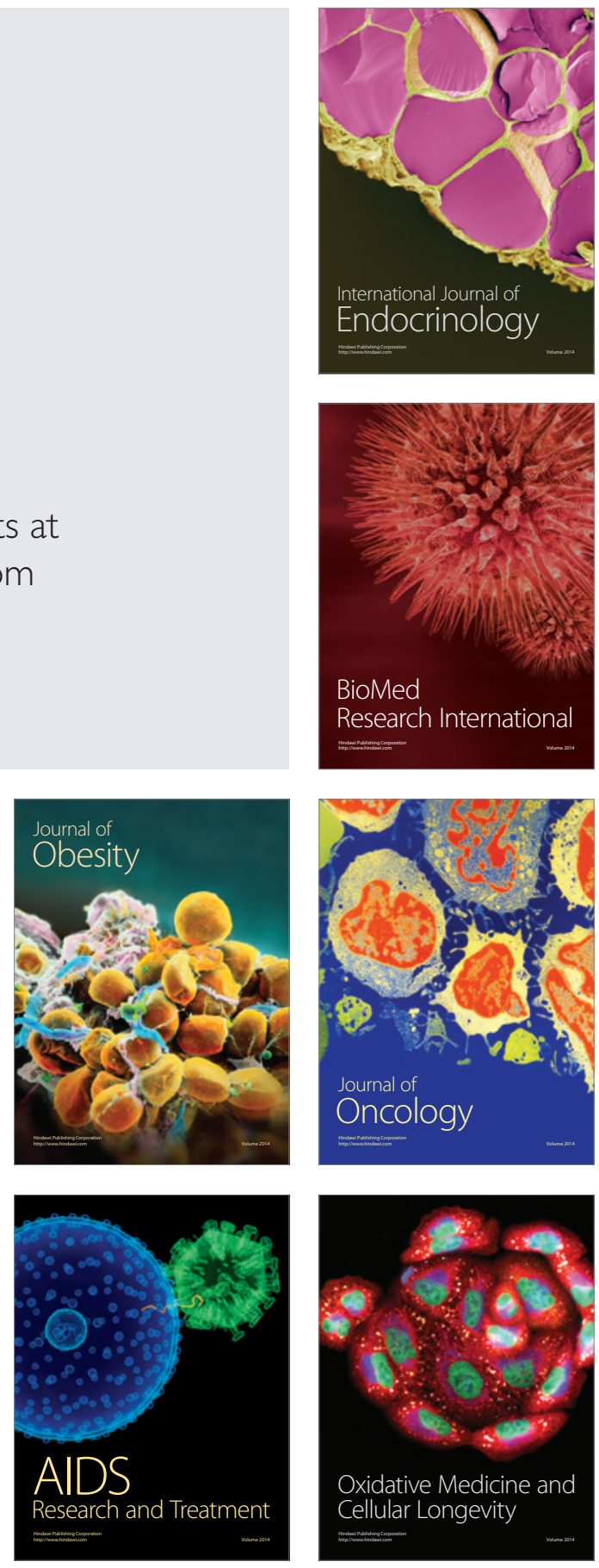